NRSIR 82-2551

\title{
Evaluating Alternative Strategies for Reducing Residential Fire Loss - The Fire Loss Model
}

U.S. DEPARTMENT OF COMMERCE

National Bureau of Standards

National Engineering Laboratory

Center for Fire Research

Washington, DC 20234

August 1982

Interim Report

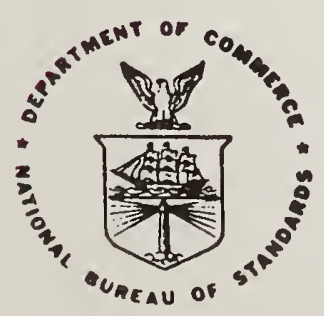

$-Q C-$ 



\section{EVALUATING ALTERNATIVE STRATEGIES \\ FOR REDUCING RESIDENTIAL FIRE \\ LOSS - THE FIRE LOSS MODEL}

Alan Gomberg and Benjamin Buchbinder

U.S. DEPARTMENT OF COMMERCE

National Bureau of Standards

National Engineering Laboratory

Center for Fire Research

Washington, DC 20234

and

Fred J. Offensend

Decision Analysis Group

SRI International

333 Ravenswood Avenue

Menlo Park, CA 94025

August 1982

Interim Report 

LIST OF FIGURES . . . . . . . . . . . . . . . . . . . . . . . . . iv

LIST OF TABLES . . . . . . . . . . . . . . . . . . . . . . . v

Abstract . . . . . . . . . . . . . . . . . . . . . . 1

1. INTRODUCTION . . . . . . . . . . . . . . . . . . . . . . . . . 1

2. OVERVIEW OF THE RESIDENTIAL FIRE DECISION ANALYSIS FRAMEWORK . . . . . . . 2

2.1 Demographic Model . . . . . . . . . . . . . . . . . . 3

2.2 Alternative Selection and Implementation Model ........... 3

2.3 Fire Loss Model . . . . . . . . . . . . . . . . . . . . . 5

2.4 Cost Model . . . . . . . . . . . . . . . . . . . . 6

2.5 Value Model ........................... 7

2.6 Calculation of Cost plus Loss . . . . . . . . . . . . . . 7

3. LOSSES UNDER CURRENT CONDITIONS . . . . . . . . . . . . . . . . . . . 7

3.1 Ignition Probability . . . . . . . . . . . . . . . . . 8

3.2 Probability of Fire Being Reported . . . . . . . . . . . . . . . 8

3.3 Fire Scenario Probabilities . . . . . . . . . . . . . . . . . . 8

3.4 Detector Presence Probability . . . . . . . . . . . . . . . . . . 9

3.5 Fire Size at Start of Suppression Activity (Suppression Size) . . . . 10

3.6 Extent of Flame Damage Probabilities................... 11

3.7 Loss Assignments . . . . . . . . . . . . . . . . . . . . . 12

3.8 Calculation of Losses Under Current Conditions . . . . . . . . . . 12

4. LOSS REDUCTION UNDER THREE ALTERNATIVE INTERVENTION STRATEGIES • • • • . 12

4.1 Residential Sprinkler Systems . . . . . . . . . . . . . . . 13

4.2 Smoke Detectors . . . . . . . . . . . . . . . . . . . . 15

4.3 Joint Installation of Sprinklers and Smoke Detectors . . . . . . . . . 17

4.4 Comparison of Relative Benefit of Alternatives . . . . . . . . . . 17

5. SENSITIVITY ANALYSIS . . . . . . . . . . . . . . . 18

5.1 Detector Performance . . . . . . . . . . . . . . . . . 18

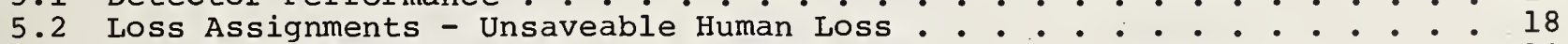

5.3 Sprinkler Effectiveness . . . . . . . . . . . . . . . . . 19

5.4 Unsaveable Human Loss/Sprinkler Effectiveness . . . . . . . . . . . . 19

5.5 Detector Impact on Unreported Fires . . . . . . . . . . . . . 19

6. CONCLUSIONS . . . . . . . . . . . . . . . . . . . . 22

7. REFERENCES .......................... . . . . 23

APPENDIX A. PROBABILITY TREE CALCULATIONS . . . . . . . . . . . . . . 57 
Figure 1. Schematic of the Residential Fire Decision Analysis Model . . .

Figure 2. Components of Demographic Model . . . . . . . . . . . . . 25

Figure 3. Components of Alternative Selection and Implementation Model • 26

Figure 4. Schematic of Fire Loss Model . . . . . . . . . . . . . . . . 27

Figure 5. Probability Tree for a Single Scenario . . . . . . . . . . 28

Figure 6. Probabilities for Suppression Size Given Extent of Damage . • . 29

Figure 7. Unsaveable Fatality Assessment Worksheet: Sprinkler Alternative ... . . . . . . . . . . . . 30

Figure 8. Unsaveable Injury Assessment Worksheet: Sprinkler Alternative . 31

Figure 9. Attenuation Assessments - Sprinkler Alternative, New Homes . . 32

Figure 10. Detector Presence Probabilities after Attenuation - Detector

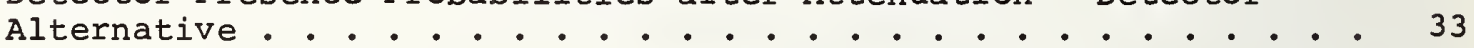

Figure 11. Unsaveable Fatality Assessment Worksheet: Detector Alternative . 34

Figure 12. Unsaveable Injury Assessment Worksheet: Detector Assessment • • 35

Figure 13. Detector Presence Probabilities after Attenuation - Sprinkler plus Detector Alternative... . . . . . . . . . . . 36

Figure 14. Unsaveable Fatality Assessment Worksheet: Sprinkler/ Detector Alternative . . . . . . . . . . . . . . 37

Figure 15. Unsaveable Injury Assessment Worksheet: Sprinkler/Detector Alternative . . . . . . . . . . . . . . . . . 38

Figure 16. Model for Calculating Detector Influence on Ignition and Reporting Probabilities... . . . . . . . . . . . 39

Figure 17. $\mathrm{pq}=0.00286$. . . . . . . . . . . . . . . . . . . 40

Figure 18. Sensitivity to Effect of Detectors on Unreported Fires . • . . 41 
Table 1. NFIRS Codes for Fire Scenarios. . . . . . . . . . . . . . . 42

Table 2. Description of Fire Scenario Groups . . . . . . . . . . . . . . . 44

Table 3. Detector Presence Probabilities . . . . . . . . . . . . . 45

Table 4. Suppression Size Assessments - Sprinkler Alternative . . . . . . . 46

Table 5. Nominal Loss Reductions for Three Alternatives . . . . . . . . . 47

Table 6. Sensitivity Analysis of Detector Performance Probabilities -

Frequency of Nonfunctional Detector . . . . . . . . . . . . 48

Table 7. Sensitivity Analysis of Unsaveable Assessments . . . . . . . . . . 49

Table 8. Suppression Size Assessments - Sprinkler Alternative . . . . . . 50

Table 9. High Suppression Size Assessments - Sprinkler Alternative . . . . 51

Table 10. Low Suppression Size Assessments - Sprinkler Alternative . . . . . 52

Table 11. Sensitivity Analysis of Sprinkler Effectiveness Assessments (Effect of Sprinklers on Suppression Size Parameter) . . . . . . . 53

Table 12. Sensitivity Analysis of Unsaveable Assessments and Sprinkler Effectiveness Assessments Combined . . . . . . . . . . . . 54

Table 13. Base Case Fire Loss Rates One and Two Family Dwellings . . . . . 55 Table 14. Sensitivity Analysis of Detector Effect on Unreported Fires . • . 56 

Alan Gomberg, Benjamin Buchbinder and Fred L. Offensend ${ }^{1}$

\section{Abstract}

This report provides a preliminary documentation of a decision analysis framework for evaluating alternative residential fire loss reduction strategies. The framework, when it is completed, will provide a systematic means for assessing the costs and losses occurring under different intervention strategies. The current report focuses entirely on the problem of assessing fire losses, as this is where most of the uncertainty on system performance occurs. Subsequent reports will address the cost of the alternatives, after which the alternatives can be compared on a comprehensive cost/benefit basis.

Three alternatives are considered in this preliminary report: smoke detectors, residential sprinkler systems with standard commercial-type sprinkler heads, and a combination of both measures. Based on the preliminary input data developed, the preliminary analysis indicates that both sprinklers and detectors are effective in reducing life loss. Detectors appear to be somewhat more effective in reducing personal losses, however, because of their earlier warning capability. Sprinklers appear to be significantly more effective than detectors in reducing property loss because of their earlier start in initiating suppression. Work is underway refining the loss model and developing a cost model so that meaningful cost/benefit comparisons of the alternatives can be conducted.

Key words: Cost/benefit; decision analysis; fire loss; fire safety; residential; smoke detectors; sprinkler systems.

\section{INTRODUCTION}

This report describes a decision analysis framework for evaluating residential fire loss reduction strategies. Motivation for the framework derives from the magnitude of U.S. residential fire losses and the cost of potential intervention strategies for reducing those losses. Reported residential fire losses are currently estimated at 6400 deaths, 61,000 injuries, and $\$ 2.4$ billion in property loss per

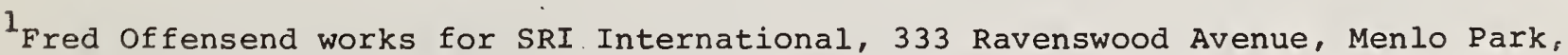
CA 94025 . 
year $[1]^{2}$. Potential loss reduction measures are available, but they are expensive. Before advocating implementation of these measures on a national basis, assurance must be obtained that they are cost-justifiable. It is the purpose of this report to develop a decision analysis framework for evaluating the cost-effectiveness of alternative residential fire loss intervention strategies.

The decision analysis methodology provides a framework for identifying decision alternatives, establishing outcome measures, and developing quantitative models for evaluating the consequences of various alternatives, given the information available. It has been successfully applied to several fire safety problems to date, including upholstered furniture fire safety [2]. Probabilistic methods are used to address uncertainty, and explicit value judgements are introduced to facilitate comparison of alternatives. Although sophisticated mathematical techniques are often employed in a decision analysis, the methodology is not a "black box" for producing results. Rather, it is a process for providing decision makers with insights into the conditions and relationships -- technical, institutional, or behavioral -- that are important in safety related decision-making.

The residential fire decision analysis framework is still in a state of development. However, the model is sufficiently far advanced that it can be used to carry out pilot evaluations of a few selected loss reduction strategies. Thus the purpose of this report is to provide an interim documentation of the decision analysis framework as used to perform preliminary benefit calculations on three specific alternatives in one and two farnily dwellings:

- residential sprinklers (using conventional commercial type sprinkler heads)

- smoke detectors

- conventional sprinklers and smoke detectors in combination.

We actively solicit comments and criticisms on how the model might be refined and extended to evaluate more fully the alternatives considered and to include a wider range of loss reduction alternatives.

\section{OVERVIEW OF THE RESIDENTIAL FIRE DECISION ANALYSIS FRAMEWORK}

The residential fire decision analysis framework provides a systematic approach for assessing the consequences of alternative loss reduction strategies. As shown in figure 1, the framework has five basic components. The demographic model specifies housing population and human characteristics of the population under consideration. The alternative selection and implementation model specifies the loss reduction strategy under consideration and calculates the extent to which the mitigation measure will be implemented and made to operate as designed. The fire loss model is used to calculates the annual residential fire losses for the target population

2 Numbers in brackets refer to the literature references listed at the end of this paper. 
in question, given a loss reduction strategy and its degree of implementation.

The value model introduces explicit value judgments to convert the physical losses calculated by the fire loss model to economic terms. The cost model calculates the total economic cost of the loss reduction strategy under consideration. Finally, the economic value of the losses is added to the economic cost to give the cost plus loss for the alternative in question. The "best" alternative is defined as the one providing the minimum cost plus loss to society.

The overall decision analysis framework is modular in format. The various submodels are designed so that they can be replaced with more complex models, or expanded, as the need arises. In this initial presentation we have focused primarily on the fire loss model since it most directly affects the evaluation of the alternatives examined.

Paragraphs 2.1 through 2.6 summarize the basic features of the various submodels.

\subsection{Demographic Model}

The demographic model specifies the target population of U.S. residences under consideration. The model can be set to include all U.S. residences or it can be made to delineate a specific type of residence. Figure $2^{3}$ gives a schematic of the kinds of factors that can be used to specify the target population. Residences are described by the housing type, size, and geographic location (which in turn provides an indication of the underlying fire risk). The occupants are characterized according to population density, socio-economic status, and ownership status. Other demographic factors can be added as the need arises to focus on particular populations. In particular, we may add some dynamic factors to the demographic model to describe more realistically anticipated changes in housing and population characteristics.

\subsection{Alternative Selection and Implementation Model}

The alternative selection and implementation model specifies the loss reduction strategy to be analyzed and the degree to which it is successfully implemented by the target population. A schematic of the model is given in figure 3 . At present, the strategies under consideration are detectors, sprinklers, and a combination of both. Additional strategies for possible subsequent consideration include building standards, product design standards, fire prevention programs, and enhancement of fire service capabilities.

${ }^{3}$ Figure 2 indicates the different values that each variable can take on. We use the notation of a circle to indicate that there is uncertainty over which value the variable will take on. The circle is called a chance node. In subsequent figures (e.g.. figure 3) there are variables such as the research funding level over which the decision-maker has control. We use the notation of a square to indicate that the decision-maker choses the value to assign to the variable. The square is called a decision node. 
Each loss reduction alternative can be implemented in several ways. The user (decision-maker) must first decide whether to use the procedure in its current state of development or whether to do further research or redesign. This decision is represented by the second factor in figure 3. Uncertainty on the research or redesign outcome is represented by the third factor. For simplicity, we have limited the two research or redesign outcomes to "success" and "failure", but in later refinements of the model, we can include a more detailed range of outcomes.

Given a particular research or redesign strategy, the decision-maker must also decide how to implement it. As indicated by the fourth factor in the figure, the implementation choices range from mandatory federal policies to free market adoption of the loss reduction strategy. Intermediate options requiring government effort might include support programs to help acquire or install the measures, encouragement of local regulation, and tax incentives. In the analysis of specific loss reduciion strategies, these implementation choices would be specified in more detail to give the exact provisions of the specific procedures.

Merely specifying a target population, loss reduction strategy, and implementation policy does not guarantee that the reduction strategy will be implemented as intended. Several factors combine to attenuate the effectiveness of the loss reduction strategy, as indicated by the remaining factors in figure 3. The first attentuation factor is the product effectiveness rate. This rate gives the probability that the product will be in operating condition when delivered to the final user. Reasons for attentuation may include materials defects, manufacturing problems, or shipping and storage difficulties. It is clear that this probability depends on the loss reduction strategy and on the extent of research and design undertaken before product development. It does not depend on the implementation strategy selected. The availability of the loss reduction technique must be taken into account. Reasons for attenuation in this area might include inadequacies of a product distribution network, reluctance on the part of distributors to handle or promote a product, regulatory constraints that prevent certain persons in the target population from participating in the program, or lack of trained people to carry out the deployment program. A third attenuation factor is the degree of user acceptance, defined here as purchasing and installing the loss reduction procedure under consideration. This factor is important in determining the overall effectiveness of the loss reduction strategy, because regardless of how effective the strategy is under ideal laboratory conditions, it will have little effect on ultimate fire losses if it is not installed by the target population. A fourth source of attenuation is the misuse or misapplication that occurs under field conditions. Many of the loss reduction techniques require frequent testing and maintenance to assure operation as intended. An example of loss of effectiveness due to field effectiveness attenuation is the clogging of a sprinkler line due to corrosion and lack of maintenance. 
The effect of the four attenuating factors just described is to reduce the number of residences in the target population in which the loss reduction strategy in question is installed and operating correctly. The number of such residences is then used as a basis for calculating the effectiveness of the loss reduction strategy. In this initial formulation of the decision analysis model, we assume that the strategy will either be fully operative or inoperative in a particular residence, depending on whether attenuation criteria were met. In later refinements of the model, we can allow for intermediate levels of partial operation.

\subsection{Fire Loss Model}

The fire loss model calculates the annual fire losses for the target population, given the particular loss reduction alternative and level of implementation as specified by alternative selection and implementation model. The losses for the target population are calculated in two parts: losses for that portion of the target population that does successfully implement the alternative and losses for that portion that does not successfully implement the alternative. The losses for the portion of the population that does not successfully implement the alternative are assumed to occur at the same rate as for current conditions (without the alternative in place). Adding the losses for the two portions of the population gives the losses for the entire target population.

The difficulty in assessing fire losses under a new loss reduction strategy is that there is generally no field experience to determine the effectiveness of the alternative. Instead, judgments and extrapolations must be made based on the results of laboratory tests and other field data. To facilitate the assessment of fire losses under an unproven alternative we introduce the probability tree presented in figure 4. The tree delineates a number of conditions under which various alternatives might perform, represented by five factors. By assigning an appropriate number of values to each factor, it becomes possible to make reasonable assessments on how an alternative might perform.

The pilot residential fire loss model presented in figure 4 introduces five factors to delineate the conditions under which an alternative might perform. The model first specifies whether an ignition occurs in a residence in the target population during the year in question, and given an ignition, whether the fire is reported to fire authorities. Our present fire loss model considers only reported fire losses, but in later refinements of the model we plan to include unreported fires.

Given a reported ignition, the second factor specifies the type of fire scenario, that is, the characteristics (and in some cases the area of origin) of the fire. For simplicity, the pilot model aggregates 26 different scenarios into 9 scenario groups. These scenarios and scenario groups are described in section 3 . 
Given a reported ignition of a particular scenario, the fire loss model then specifies whether there is a functional smoke detector in the residence. To facilitate data aggregation, the model allows for three detector presence outcomes: functional detector in operating condition, installed detector in nonoperable condition (nonfunctional), and no detector present.

The fourth model factor specifies the size of fire development at the time meaningful suppression efforts are begun. Meaningful suppression efforts are defined to include manual or automated suppression efforts that would have a reasonable chance of arresting the fire development. Three possible stages of fire development and start of suppression are considered: fire confined to the object of origin $(0)$, fire greater than the object but confined to part of the room of origin $(<R)$, and fire equal to or greater than the room of origin ( $\geq R)$.

Finally, given a reported ignition of a particular scenario and a specification of detector presence and size of fire at initiation of suppression, the model allows for an assessment of the final extent of flame damage. The same three possible levels of flame damage are considered: $0,<R$, and $\geq R$. The three fire stages for the last two factors were selected to reflect the stages in the fire growth at which the alternatives might impact. It was not considered relevant to distinguish between fires of full room involvement and those of still greater involvement.

Each of the variables in figure 4 can take on the different values indicated on the branches in the figure. Combining the different branch values provides a large number of paths through the tree. Associated with each path through the tree is a level of loss. Probabilities are assigned to the branch values for each factor. Probability assignments are discussed in detail in subsequent sections. Multiplying the probabilities for the different branches comprising a given path gives the probability for that path. Associating the probability for each path with the path outcome then enables a probability distribution to be constructed showing the range and likelihood of different loss outcomes. The probability distribution is the logical implication of the uncertainties on the six input factors to the fire loss model.

\subsection{Cost Model}

A cost model must develop the total implementation cost of the loss reduction measure under consideration. All research, installation, operation, maintenance, and enforcement costs must be included in the cost calculation. Where costs are incurred in different years, they should be annualized at a nominal discount rate so that the costs can be compared on a consistent basis. In this initial version of the residential decision analysis framework costs of the alternative are not addressed, nor is the distribution of costs versus benefits for the population as a whole. In subsequent work, we will address detailed costs, and develop cost plus loss criteria. 


\subsection{Value Model}

The output of the fire loss model gives the number of deaths and injuries and amount of property damage under the intervention strategy in question. In principle the decision-maker could compare these different outcomes with the cost of the alternative to determine whether the loss reduction measure is cost-justifiable. The problem with this approach, however, is that it is difficult to ensure consistency in value judgments from one decision problem to another, as there is no widely accepted basis for direct comparison of the "value of life" to the dollar value of property. In one situation an alternative might be selected that implies a value of saving a human life of $\$ 1,000,000$. In another situation, the implied value might only be $\$ 10,000$. Such inconsistencies could lead to an inequitable allocation of resources, since in one situation an alternative would be accepted which would be rejected in another situation.

To ensure consistent value trade-offs from one decision problem to another, we introduce an explicit set of value trade-offs to convert the various categories of personal loss to economic terms. The trade-offs give the dollar amount that society is willing to pay to avoid a fire death or burn injury. Converting the personal losses to monetary terms then allows the non-monetary losses and economic costs to be compared on a common scale.

We recognize the difficulty of determining a value for saving human life. It is doubtful that a consensus for these values will ever be reached among all members of society. Ignoring the trade-off problem will not eliminate the problem, however, because value trade-offs, either implicit or explicit, are made every time an expenditure is made (or denied) for public safety.

\subsection{Calculation of Cost Plus Loss}

The monetary equivalent of the fire losses is added to the economic costs to give the cost plus loss under the mitigation measure in question. All time streams of costs and losses are annualized to equivalent annual amounts of costs and losses, so that they can be compared on a consistent basis. From an economic standpoint the most attractive alternative is the one with the least total cost plus loss, since any other alternative would cost society more, whether that cost be an economic expenditure or dollar equivalent of losses.

\section{LOSSES UNDER CURRENT CONDITIONS}

We first use the decision analysis framework to calculate total residential fire losses under current conditions. Setting the models to reflect current conditions provides a known and measureable reference for analyzing the alternatives. Once the models have been calibrated to reflect current conditions, the individual parameters can be adjusted to describe the performance of the various loss reduction strategies. 
This section therefore begins with a presentation of the input data used to model current conditions and concludes with a summary of the results. Wherever possible we have used statistical information from the National Fire Incident Reporting System (NFIRS) and other data sources to establish the input data. However, if the desired data were not available, or if there are known biases in the data, then we used expert judgment to develop the input data, since that is the best information available to us. Whenever possible, judgment is supported by some type of data, often data which are not directly applicable to the model but which set bounds on, or assist in, making judgments.

\subsection{Ignition Probability}

The U.S. Fire Administration (USFA) estimates that there were $32,690,000$ fires in the U.S. during 1978 [1]. Of these fires, 26 percent, or 8,499,000 fires, were estimated to be residential fires. Seventy-three percent, or 6,204,000 of the residential fires were estimated to occur in one and two family dwellings, the occupancies of interest in this study. Comparing the number of one and two family dwellings that had a fire in one year with the total number of such dwellings, $61,000,000$ (estimated from Census tabulations), gives a probability of ignition of $6,204,000 / 61,000,000=0.102$.

\subsection{Probability of Fire Being Reported}

Of the $32,690,000$ estimated fires in 1978, the USFA reports that $2,690,000$ ignitions were reported to the fire service. Thus, the probability of an ignition being reported to the fire service is $2,690,000 / 32,690,000=0.082$. For simplicity, until better data become available, we assume that this probability applies to one and two family dwelling fires, as well as to the population of all fires for which it was calculated. Multiplying the probability of a fire in a one or two family dwelling by the probability that it is reported gives a probability of 0.008 that there will be a reported fire in a one or two family dwelling in a given year.

\subsection{Fire Scenario Probabilities}

A primary difficulty in planning for residential fire safety is that there are so many different kinds of fires, in terms of such factors as ignition source, materials ignited and location. Since the effectiveness of loss reduction strategies depends on the kind of fire, or scenario, the fire loss model explicitly includes the probabilities of the different fire scenarios. As a starting point we define 26 different fire scenarios which are identified using the NFIRS encoding format [3] as specified in table 1. The fire scenarios are defined in a hierarchical way. That is, if a fire can be classified into one of several scenarios, it is assigned to the lowest numbered category. Thus, for example, a flammable liquid fire occurring at the exterior of the dwelling is classified as an exterior fire (scenario no. 1), and not a flammable liquid fire (scenario no. 5). The categories are arranged so that the more critical a scenario is, in terms of differences between 
it and other scenarios in response to the loss reduction measures being considered, the lower its number is, and the higher it occurs in the hierarchy. Exterior fires, for example, are scenario no. 1 because they are not significantly affected by any alternatives, which are concerned only with interior fires. In fact, review of the scenario components reveals very little overlap between scenarios.

For ease in computation we collapse the 26 scenarios into a smaller number of groups, where the scenarios within each group have similar characteristics with respect to response to the loss reduction measures being studied. For the purpose of the alternatives investigated in this phase of the study, it is possible to collapse the 26 scenarios into the nine groupings identified in table 2 . The table gives the nine scenario groups, the various scenarios which make up each group, and the probability for each group.

The probabilities of fire scenario groups as given in table 2 are for reported fires only, based on NFIRS data. Unless otherwise indicated, the remaining probabilities given in this section are for reported fires only. In later applications of the decision analysis model, we will develop input probabilities for unreported fires.

\subsection{Detector Presence Probability}

Three possible states of detector performance are considered by the decision analysis model: detector present and operable (functional), detector present and did not operate (non-functional), and no detector present (none). The NFIRS data base includes these categories, but subdivides the "detector present" category to detector present in the room and detector present in adjoining space. For simplicity we have combined these two detectors present categories as well as the category "detector present, but fire too small or remote to operate" into one category of "functional" detector present.

In reviewing the NFIRS data, however, it is apparent that a number of fires were classified as "detector present but did not operate" when the fire was too small or remote to actuate the detector. To reflect more realistically the fraction of detectors that actually function, we have reviewed the fire scenario and final extent of flame damage for the fires nominally classified as "did not operate" and shifted those fires for which the fire was too small or remote to activate the detector to the "functional" category. Table 3 describes how each detector state was defined and gives the final probabilities of detector presence as used in this report. 


\subsection{Fire Size at Start of Suppression Activity (Suppression Size)}

The size of fire at the start of suppression activity is an important variable because it represents a lower bound on possible fire growth limitations. The NFIRS data base does not give probabilities for this variable because it only gives data for the fire conditions after the fire was extinguished. Therefore we used expert judgment to assess the size of the fire at the start of suppression activity.

The size of fire at the start of suppression activity is most readily assessed as conditional on detector presence and final extent of flame damage. The conditional assessments can be left dependent on detector performance because the suppression size variable follows the detector presence variable in the probability tree (figure 5). However, the assessments conditioned on final extent of flame damage must be collapsed, because the suppression size variable used in the probability tree precedes the final extent of flame damage.

As an example of how the probability assignments are coalesced, the probability of a particular initial suppression size is equal to the probability of initial suppression given a particular final extent of flame damage, multiplied by the probability of that extent of flame damage, summed over all final extents. Thus, the probability of the initial suppression activity occurring when the fire was confined to the object is:

$$
P\left(O_{S}\right)=P\left(O_{S} / O_{f}\right) P\left(O_{f}\right)+P\left(O_{S} /<R_{f}\right) P\left(<R_{f}\right)+P\left(O_{S} / \geq R_{f}\right) P\left(\geq R_{f}\right)
$$

where:

$P(x / y)=$ the probability that $x$ occurs given that $y$ has occurred, and

$o_{s}=$ initial suppression activity occurs when fire is confined to object

$\mathrm{O}_{f}=$ final extent of flame damage is confined to object

$<R_{f}=$ final extent of flame damage is greater than object but confined to part of room

$>R_{f}=$ final extent of flame damage is equal to greater than room

The same basic equation holds for initial suppression sizes $<R_{S}$ and $>R_{S}$, with $<R_{S}$ or $\geq R_{S}$ substituted for $O_{S}$. Also, the same equation applies for the different detector presence states; the various assessments must merely be conditioned on the detector state under consideration. The assessments for suppression size probabilities were made by the project team and are given in figure 6 . For scenarios $A$ or $B$ and for the "no detector" path, for example, the assessments indicate that if the eventual fire damage is equal to or greater than the room of origin, the probability that suppression started in the object of origin is 0.02 . The probability that suppression started when the fire was beyond the object, but still confined to part of the room is assessed at 0.04 , and the probability that suppression started at full room or greater involvement is 0.94 . For these relatively severe scenarios, the assessments imply that suppression activities starting before the room is fully involved will be successful in preventing the fire from growing to full room or 
greater size in all but 6 percent $(0.02+0.04)$ of the cases and for the least severe scenarios (C, F, G, H) will do the same in all but 3 percent $(0.01+0.02)$ of the cases.

Similar assessments are made for those cases wherein the eventual fire damage is confined to part of the room of origin. For scenarios A or B the probability that suppression activity started in the object of origin, given that the final extent of damage is part of room is assessed at 0.30 . The remaining 0.70 is therefore the probability that suppression started at the same level as the extent of damage, part of room. If the final extent of damage is the object of origin, the suppression must, of course, have started in the object of origin.

The assessments made for the no detector paths are used for the non-functional detector paths as well; similar assessments (in parentheses) were made for the functional detector paths. Calculated probabilities are given in appendix A.

\subsection{Extent of Flame Damage Probabilities}

The probabilities of final extent of flame damage can be calculated directly from the NFIRS data base. These probabilities are conditioned on scenario and detector presence, but not size of fire at initial suppression. Thus, these probabilities must be adjusted to reflect the dependence on initial suppression size.

Using the definition of conditional probability, the probability of final extent of flame damage given initial suppression size can be expressed as:

$$
\begin{aligned}
P(F / S) & =\frac{P(F S)}{P(S)} \\
& =\frac{P(S / F) P(F)}{P(S)}
\end{aligned}
$$

where:

$$
\begin{aligned}
\mathrm{P}(\mathrm{xy}) & =\text { the probability that } \mathrm{x} \text { and } \mathrm{y} \text { occur together, and } \\
\mathrm{F} & =\text { final extent of flame damage }(0,<\mathrm{R},>\mathrm{R}) \\
\mathrm{S} & =\text { size of fire at initial suppression }(0,<\mathrm{R},>\mathrm{R})
\end{aligned}
$$

The probabilities "P(S/F)" are assessed subjectively by the project team. The probabilities "P(F)" are taken directly from the NFIRS data base. The probabilities "P(S)" are the probabilities for initial suppression size as calculated in the previous section. All probabilities here are conditioned on detector presence and scenario, but for clarity of notation, we have dropped this dependency.

The desired probabilities of final extent of flame damage, conditioned on scenario, detector presence, and initial suppression size can therefore be calculated according to the above equation. An example of the probability assignments for these dependencies is given in appendix $A$. 


\subsection{Loss Assignments}

The NFIRS data base gives property and human losses as a function of scenario, detector presence, and final extent of flame damage. For the purpose of calculating losses under current conditions we can use these statistics to represent the average losses under all three initial suppression sizes, since current losses can be directly related to extent of flame damage. In subsequent sections, where we investigate loss reduction strategies that affect human losses independent of extent of flame damage, we must further subdivide the loss rates. However, we defer those adjustments until the actual alternatives are considered. An example of loss rates by scenario, detector presence, and final extent of flame damage is given in appendix A.

\subsection{Calculation of Losses Under Current Conditions}

The fire loss model is employed using the parameters just described to calculate the expected losses under current conditions. The results show that the average reported one and two family residential fires in this study results in 0.00632 deaths, 0.066283 injuries, and $\$ 4479$ in property loss. These results correspond closely with the respective loss rates calculated directly from the NFIRS data base.

The significance of the calculation is not so much that we have calculated the magnitude of residential fire losses for the first time; they could have been calculated from the NFIRS statistics directly. The significance is that we have conditioned assessment of residential fire losses based on a set of variables that later can be used to model the performance of as yet unproven loss reduction strategies. In the following sections we will use this base case assessment of the conditioning factors as a reference point for modeling the performance of new loss reduction strategies.

\section{LOSS REDUCTION UNDER THREE ALTERNATIVE INTERVENTION STRATEGIES}

In this section we demonstrate the use of the decision analysis model with a preliminary evaluation of three intervention strategies. We consider loss reduction strategies involving installation of sprinklers in newly constructed housing, installation of smoke detectors in all new and existing housing, and a combination program involving both sprinklers and detectors in newly constructed housing. As the overall decision analysis model is still being developed, this demonstration analysis focuses only on the loss reduction capabilities of the three alternatives. 


\subsection{Residential Sprinkler Systems}

The sprinkler alternative is defined as follows:

Sprinkler Alternative - A conventional sprinkler system, utilizing standard commercial type sprinkler heads, installed in all dwelling spaces except baths, closets, attics, garages and similar spaces. The newly designed "fast response" residential sprinkler heads are not evaluated in this alternative but will be the subject of a future evaluation. The sprinkler option is based on installation in new homes only, under a mandated system. Detectors are not installed as an adjunct to the system, but are assumed to be present at the current national rate based on voluntary and locally mandated detector installation.

It is important to note that the benefits of this alternative apply only to new homes as projected for the future.

We first examine the effectiveness of sprinklers given that they are installed and operating properly. We then analyze the effect of the various attenuating factors that combine to make sprinklers work less effectively than in the ideal case.

The effect of sprinklers is to shorten the time to effective suppression and thus contain fires at a smaller size. In terms of the residential fire decision analysis model, the effect of sprinklers is to increase the probability that effective suppression will begin when the fire is small (correspondingly decreasing the probability that suppression will begin when the fire is large). We can therefore model the loss reduction potential of sprinklers by adjusting the probability of fire size at the start of initial effective suppression.

Sprinklers have different degrees of effectiveness in limiting fire spread, depending on the scenario. For example; sprinklers would be quite effective in limiting fire spread in living spaces that are protected by sprinklers, but would have less effect on fires that start in areas that are not protected by sprinklers (e.g. closets and crawl spaces). Thus, different assessments on time of initial suppression must be made for different scenarios.

Table 4 shows how the base case probabilities of fire size at time of initial suppression are changed to reflect the presence of sprinklers. The adjustment rules were subjectively developed by the CFR/SRI project team based on their combined experience, and on considerations involving the relative locations of the fires and nearest sprinkler heads, and the ignition characteristics. As an example of the adjustment rules, the table shows that for interior living space fires (Scenario G) and for fires in which the initial object ignited is not large (e.g. wastebasket), the probability of suppression size $>R$ is reduced by 100 percent under the sprinkler 
alternative. Ninety percent of the " $>R$ " probability is added to the original " $<R$ " probability and the other 10 percent to the "O" probability, because a relatively small initial object is less likely to activate the system before other materials become involved.

While property losses are directly related to final extent of flame damage, human losses are often not directly related to final flame spread because the losses may occur at an early stage in the fire. Property losses for this alternative are developed by using the decision analysis model to calculate the revised distribution on extent of flame damage, given the new suppression size probabilities, and then relating the final extent of flame damage to expected property losses according to the loss experience reported in the NFIRS data base.

In those situations where human loss may be independent of extent of flame damage, and where the alternative has the effect of reducing final extent of flame damage only, it is not appropriate to use the extent of flame damage to model human losses. To address this problem we divide the population of potential victims into two groups: those that could possibly be saved by the intervention strategy are "saveable", and are dependent on the final extent of flame damage, and those that would have no chance of being saved by the alternative are classed as "unsaveable". A casualty occurring due to clothing ignition is an example of an individual who would be classified as "unsaveable" under the sprinkler alternative, because the sprinkler would not be activated until the fire was large enough to cause the casualty.

Separate assessments of the unsaveable rate are made for injuries and deaths because sprinklers impact differently on different kinds of losses. Similarly, different assessments are made for different intervention strategies. Once the unsaveable assessment is made, we set aside the unsaveable population. Human losses for the saveable population are calculated by multiplying the revised distribution on extent of flame damage by the base case loss rates for each extent of flame damage category. The losises calculated for the saveable population are then added to the losses set aside for the unsaveable population to give the total human losses under the alternative being considered.

The saveable/unsaveable assessment is made according to the casualty status at time of ignition and the casualty action at time of injury. Figures 7 and 8 give the worksheets that were used to calculate the unsaveable fatalities and injuries respectively for the sprinkler alternative. The figures give nine possible casualty statuses and eight possible casualty activities. The numbers in the matrix entries give the number of observed casualties of the designated type in the NFIRS data base. The shaded entries indicate the casualty types that would be unsaveable under the sprinkler alternative. Dividing the shaded matrix entries by all of the entries results in 32.6 and 13.2 percent, respectively, of the current fire deaths and injuries being judged to be unsaveable under the sprinkler alternative. 
Our analysis of sprinkler effectiveness must account for the possibility that sprinklers will not be installed or that they will not perform as intended. As a preliminary assessment of that attenuation, we consider the four attenuating factors shown in figure 9. For example, for mandatory regulation in new homes we assume that 0.999 of the sprinkler systems will be correctly manufactured at the factory. We assume that 0.95 of all residences will find sprinklers available for purchase, and that 0.97 of those residences will have the systems installed. Finally, we assume that $0.92^{4}$ of the sprinkler systems will be properly maintained and will operate effectively. The net effect of these four attenuating factors is that 84.7 percent $(0.999 \times 0.95 \times 0.97 \times 0.92=0.847)$ of all new homes are assumed to have operative sprinkler systems under the sprinkler alternative in this analysis. Since statistics to support these assumptions are not available, the sensitivity of cost plus loss comparisons of alternatives to these assumptions must be determined before decisions on alternative selection are made.

Total losses under the sprinkler alternative are calculated in two parts. If the home does not have an operative sprinkler or if the occupant classification is "unsaveable", then the loss rate is set equal to the current loss rate. If there is a working sprinkler system and if the occupant is classified as "saveable" then we use the model to calculate the revised distribution of final flame extent given the suppression activity of the sprinkler. The human losses for this latter group are calculated as a function of final extent of flame damage, using the loss rates observed under current conditions. The losses for the two population groups are then summed to give total losses under the sprinkler alternative.

The input data for modeling sprinkler losses consists of the base case data adjusted to reflect the suppression size probabilities for the sprinkler system (table 4), the assessments on the size of the saveable population (figures 7 and 8 ) and the attenuation factors on effective installation (figure 9). Using this data base the model calculates reductions for the sprinkler system alternative of about 34,17 , and 38 percent in deaths, injuries and property losses respectively compared to current conditions. We will return to these reduction rates in a later section to examine how the reduction rate changes with changes in the input data.

\subsection{Smoke Detectors}

A second alternative for reducing residential fire losses is to require installation of smoke detectors in all old and new residences.

\footnotetext{
${ }^{4}$ Note that this estimate of reliability is somewhat lower than that usually given for commercial occupancies, due to the likelihood that residential installations may be less controlled and inspected less regularly than commercial installations.
} 
Detector Alternative - One or more smoke detectors, as necessary, to protect sleeping areas, are installed. It is assumed that additional voluntary multi level installation will result in a distribution that reflects the current mix of detectors in the population. The alternative is implemented through regulation requiring minimum detector protection in all occupied homes (new and existing). Benefits of this alternative apply to both the current and future population of homes.

Two adjustments must be made to the base case data base to model the performance of smoke detectors. We must assess the fraction of homes having operational detectors under a fully implemented detector policy, and the fraction of the population that would be saveable under a detector policy.

According to the NFIRS data base, 14.4 percent of all residences with reported fires had smoke detectors, 12.7 percent functional and 1.7 percent non-functional. Therefore, 88.19 percent of the detectors present were indicated as functional. As shown in figure 10, we assume there will be 95 percent availability of detectors if the mandatory detector policy is implemented. We assume that 95 percent of the residences without detectors will purchase them and that the functional/non-functional rate will be the same as under current conditions. The net result is that 80.84 percent of the residences with reported fires are assumed in this analysis to have functional detectors; 10.81 percent are assumed to have non-functional detectors; and 8.35 percent are assumed to have no detectors at all. As previously described, sensitivity analysis of these assumptions will be undertaken in future work due to the lack of statistics in these areas.

We use the same classification system to assess the unsaveable portion of the population as was used for sprinkler systems. The assessments are different, however, because detectors perform differently from sprinkler systems. Figures 11 and 12 give the unsaveable assessments for fatalities and injuries under the detector alternative. Clothing ignited casualties are unsaveable, as are "response/return" and some "intimate with ignition" casualties. Those intimate with ignition sleeping fatalities are considered saveable, as detectors have a chance to wake them up before the casualty occurs. Casualties located in the room of origin at ignition and who were "awake at ignition" are considered unsaveable, as they should have been able to detect the fire and respond to it prior to detector operation. The net effect of the unsaveable assessments in figures 11 and 12 is that 14.0 and 15.8 percent, respectively, of current deaths and injuries are judged to be unsaveable under the detector alternative.

The loss model calculates the loss reduction effectiveness of detectors using the revised probabilities on detector presence and the unsaveable assessments previously described. The results give reductions compared to current conditions of 41,4 and 16 percent, respectively, for deaths, injuries, and property loss. 


\subsection{Joint Installation of Sprinklers and Smoke Detectors}

A third alternative for reducing residential fire losses is to require the joint installation of sprinklers and detectors, in the manner previously defined under each separate alternative, in all new residences. The intent of the alternative would be to provide early effective suppression through the sprinkler system and early warning to the occupants through the detector system. In principle, detectors could be installed in existing residences as well, but for purposes of clarity, we consider only new residences.

To model the combination system we must adjust the base case suppression size probabilities to reflect the presence of the sprinklers, and adjust the detector presence probabilities to reflect the increased installation of detectors. We must also model the atienuating factors and the unsaveable portion of population. We use the same suppression size and attenuation probabilities as for the sprinkler alternative because the sprinkler system will operate the same under the "joint" and "sprinkler only" alternatives. As shown in figure 13, we assume that detectors will be more widely available and accepted into new homes. Thus, we derive an 85.9 percent probability of there being a functional detector under the combination alternative; an 11.5 percent probability for non-functional detectors, and a 2.6 percent chance of there being no detector at all. As shown in figures 14 and 15 , we calculate unsaveable rates of 12.3 percent for deaths and 11.4 percent for injuries.

Based on the input data just presented, the decision analysis model calculates reductions compared to current conditions of 58, 18, and 46 percent, respectively, for deaths, injuries, and property loss.

\subsection{Comparison of Relative Benefit of Alternatives.}

Table 5 summarizes the nominal reduction rates for the three alternatives considered. The table indicates, based on the previously described preliminary efforts, that significant reductions in loss may be achievable under any of the three alternatives. In terms of total loss reduction, the greatest reduction appears to be under the combination alternative. But if only one protection system is to be implemented, then these preliminary results indicate that greatest fatality reduction occurs under the detector alternative, and the greatest injury and property loss protection occurs under the sprinkler alternative.

If the decision using this information were to be made on the basis of loss reduction, the choice would be to implement a joint program of sprinklers and detectors. But this alternative is costly and it could take several years for the benefits of this alternative to be realized in a significant way. Thus the cost effectiveness of each alternative should be examined before selecting an optimal strategy from the three presented here. 
As discussed earlier, a detailed cost model which enables the calculation and comparison of costs and losses over time is currently being developed. In addition, recent changes in sprinkler technology may require modification of the sprinkler alternative, to consider the "fast response" sprinkler head. Thus, we postpone beyond this preliminary report a cost/benefit comparison of the alternative intervention strategies.

\section{SENSITIVITY ANALYSIS}

Sensitivity analysis is a systematic approach for evaluating the extent to which our nominal results are affected by changes in input assumptions. The residential fire loss reduction alternatives are reevaluated using plausible alternative values for individual model parameters. If the ranking of the alternatives changes with variations in the value of a particular parameter, then additional evidence about the value of that parameter may need to be collected. The remaining variables can be fixed at their nominal values for further analysis of the alternatives in question. Sensitivity analysis helps to guide the model building and data gathering effort as it enables us to focus our attention on the factors that most critically affect the evaluation of alternatives.

The following discussion summarizes the sensitivity analysis conducted on our loss reduction results to date. Other analyses incorporating the costs of the mitigation measures or other input assumptions will be carried out as the need arises.

\subsection{Detector Performance}

The nominal value of 11.8 percent nonfunctional detectors in dwellings was varied from a high value of 25 percent to a low value of 5 percent for the detector and sprinkler/detector alternatives. The smoke detector results are slightly more sensitive than the sprinkler/detector alternatives to changes in the value of this parameter, as shown in table 6 . However, the relative ranking of the alternatives in question does not change. Additional evidence about the likelihood of nonfunctional detectors in dwellings may therefore not be required in the evaluation of these three alternatives.

\subsection{Loss Assignments - Unsaveable Human Loss}

Sensitivity analysis was carried out on the probabilities of unsaveable injuries and deaths for all three alternatives. Low, nominal and high values for these probabilities are listed in table 7. Although the results for the sprinkler and sprinkler/detector alternatives are more sensitive to changes in these values than the results for the detector alternative, the relative ranking of alternatives does not change. 


\subsection{Sprinkler Effectiveness}

Alternative assessments were made of the size of fire development at the start of effective suppression activity for the sprinkler and sprinkler/detector combination alternative. The original assessments are given in table 8 and the high and low assessments are given in tables 9 and 10, respectively. Although the results of this sensitivity analysis, given in table 11 , indicate that a choice between alternatives based on loss reduction rates would not be affected by changes in the level of sprinkler effectiveness, it is possible that some effect could be felt when cost plus loss is considered. The high assessment is particularly important since it represents a faster acting sprinkler than the conventional sprinkler on which the original assessments are based, and may be indicative of the potential for greater loss reductions under a fast response sprinkler alternative than are currently projected for conventional sprinklers.

\subsection{Unsaveable Human Loss/Sprinkler Effectiveness}

Estimates of unsaveable personal loss and sprinkler effectiveness depend on the speed of operation of a sprinkler head. Therefore, a joint sensitivity analysis on the values of these parameters was carried out to provide insight into the potential of faster acting sprinklers. The results of this analysis, summarized in table 12, indicate that the choice between the alternatives (on a loss reduction basis alone) would not be influenced by changes in these values, although the overall reductions under the sprinkler alternative are virtually the same as the reductions under the detector alternative for the low assessment.

\subsection{Detector Impact on Unreported Fires}

Fire incident data (NFIRS) for the 1977-79 period indicate that detectors were present in about 12 percent of the fires reported to the fire service. Estimates of detector installation in homes nationally for that period indicate that about 35 percent of the homes in the country were provided with one or more smoke detectors. Two possible reasons for this discrepancy have been identified [4]:

- The voluntary purchase factor - people who voluntarily purchase and install detectors may have fewer ignitions for various reasons, primarily greater fire safety awareness than the general populace, and higher socioeconomic level.

- The unreported fire factor - fires which would develop into reported fires without detectors present may not do so with detectors present, because early detection enables occupant extinguishment while the fire is very small. Unreported fires (and unreported fire fatalities) are those not reported to the fire department, and which therefore do not appear in the data base. Other sources, such as death certificate and special studies are used to develop estimates of the magnitude of unreported fires and fire fatalities. 
The potential for early detection to "transform" potential reported ignitions into unreported fires may have substantial impact on overall losses. However, because the information available on unreported fires is extremely limited, it is not possible to make reasonable quantitative estimates of the extent of impact of this factor on overall fire losses at this time. It is therefore necessary to estimate possible impacts and test the sensitivity of the results under the Detector Alternative to these estimates.

The first step in this process is to assign base case losses to unreported fires, so that new base case losses for all fires (versus losses for reported fires only, used throughout this report) can be calculated. These losses were calculated in the following manner.

It is estimated by various sources that 5-10 percent of all fire-related fatalities occur in unreported fires. For the purposes of this study 7.5 percent was used. From Highlights of Fire in the United States, Second Edition [1], the total fire deaths in one- and two-family dwellings can be approximated by multiplying total deaths $(8400)$ by the percent in residences $(77 \%)$ by the percentage of residential fires in one- and two-family dwellings (73\%), giving a total of 4,722 deaths in reported and unreported fires. Assuming 7.5 percent are in unreported fires gives a total of about 354 deaths annually. A similar estimating process is used to calculate the number of unreported fires annually, which equals $30,000,000 \times 0.26 \times 0.73$ or about 5,700,000 unreported fires in one- and two-family dwellings annually. This represents a loss rate of 0.000062 fatalities per fire, or 62 fatalities per 1,000,000 fires. Injuries can be obtained from the Highlights report in a similar manner, that is 200,000 injuries not reported multiplied by the percent of injuries in residences ( $68 \%$ ) by percent of residential fires in one- and two-family (738) for a total of 99,280 injuries in 5,700,000 fires, or a rate of about 17,400 per 1,000,000 unreported fires. Property loss is estimated at $\$ 450$ per unreported fire. From these estimates and the base case losses for reported fires, an estimate of loss rates for all fires can be calculated using the probability assignments for reported and unreported fires given in Sections 3.1 and 3.2. These loss rates are summarized in table 13.

The next step is to develop a model to evaluate the possible effects of detection on ignition and reporting probabilities. The model used is illustrated in figure 16. The path probability of 0.0010 for the reported ignition path is derived from NFIRS data which indicate that detectors are present in 12 percent of reported fires. The overall probability of a reported fire, from section 3.2 is $0.102 \times 0.082$ $=0.00836$. The probability of a reported ignition, given a detector present, therefore, is $0.00836 \times 0.12=0.0010$. This probability is a constant, as it is fixed by available data. The "buy detector" probability of 0.35 is also a constant, as it represents detectors installed in 35 percent of all homes. The relationship between $p$ (the probability of ignition, given detection) and $q$ (the probability that ignition is reported, given detection) is therefore given by the equation pq $=0.0010 \div 0.35$ (the "buy detector" probability), or pq $=0.00286$. 
This relationship, $\mathrm{pq}=0.00286$, is graphically represented in figure 17 . The portion of the curve which we are interested in is bounded by the points, from Sections 3.1 and 3.2 at which the presence of detection does not influence the probability of ignition ( $p=0.102$, with a corresponding $q=0.028$ ) and the point at which the presence of detection does not influence the probability of a fire being report $(q=0.082$, with a corresponding $p=0.035)$. These points represent the upper and lower limits of the effect of detection on reported ignition.

From the curve we select three points which approximate 25 percent, 50 percent, and 75 percent of the effect of detection on fire reporting (with the corresponding 75 percent, 50 percent, and 25 percent on the effect being on ignition. These points are:

Effect on

Reporting

$\underline{\mathrm{p}} \quad \underline{\mathrm{q}} \quad \underline{1-\mathrm{q}}$

$25 \%$

0.042

0.068

0.932

$50 \%$

0.060

0.048

0.952

$75 \%$

0.084

0.034

0.066

Losses under each alternative for both reported and unreported fires are then calculated under the assumption that detection has no effect on reported ignitions. This assumption states, in effect, that the three alternatives under consideration affect reported fires only, and that cost benefit calculations should consider only reported fires. As with all the sample sensitivity analyses described here, the calculations are based on loss reductions before attenuation, for purposes of simplification. These losses, given ignition, are calculated by multiplying losses per reported fire under each alternative (the original assessments in the sensitivity analysis tables, such as table 6 ) by the base case reported ignition probability (0.082), and, multiplying the loss per unreported fire from table 13 by the base case unreported ignition probability (0.918) and summing. These losses, and the corresponding reductions from the base case of all fires are shown in table 14 as "no effect" losses.

The Iosses under each alternative for 25 percent, 50 percent, and 75 percent effect of detection on reported fires are then calculated in the same manner with $q$ representing the reported ignition probability and $1-q$ the unreported ignition probability, for the two alternatives involving detectors. The losses under the sprinkler alternative remain the same, because no effect of sprinklers alone on reported fire probability has been noted. The losses, and corresponding reductions from the base case for the three selected estimates of possible effect of detection on fire reporting are also given in table 14. 
Figure 18 depicts the results of this sensitivity analysis on Total Expected Value. The apparent sensitivity of potential loss reduction to possible effects of detectors on unreported fires is substantial. From figure 18, it appears that detectors may surpass conventional sprinklers in overall loss reduction potential if slightly over 25 percent of the discrepency between detectors in homes and detectors in reported fires is due to the unreported fire factor.

Further research, to better understand the ability of early warning detection to transform potentially large fires into minor unreported incidents is therefore a necessity in order to better understand and quantify the total possible impact of detectors on fire loss potential.

\section{CONCLUSIONS}

No definitive conclusions can be drawn from this report, due to its preliminary nature. Some general observations are possible, however.

\section{Overall Loss Reduction}

All alternatives produce benefits, in terms of fire loss reductions. The combination of sprinklers and detectors appears to produce the greatest overall reductions in Expected Value on a per fire basis, followed by sprinklers alone, and then detectors alone. The sprinkler/detector alternative produces the best results for all categories of loss (fatalities, injuries and property loss), as the strengths of both sprinklers and detectors are combined in a complementary, although not directly additive manner.

\section{Fatalities}

Detectors alone appear to be slightly (but not significantly) better than sprinklers alone in reducing fatalities. This may be due in part to the large number of fatalities which occur in the immediate vicinity of the fire origin. Detectors may prevent some of these fatalities by alerting the people involved while the fire is still small and relatively harmless, while conventional sprinklers often may not operate quickly enough to prevent death or injury in such situations.

\section{Injuries, Property Loss}

Although the early warning of detectors indicates that reductions in injury and property losses are possible, sprinklers, by actively controlling a fire, appear to produce significantly larger reductions in these loss categories. 
The potential for loss reduction from detector installation, especially in the area of life loss, is significant, and should be obtainable in jurisdictions which mandate detector installations in all homes. However, because the loss reductions calculated here are based primarily on voluntary detector installations, with a likely higher degree of fire consciousness in the installing population, a simple requirement for installation of detectors may not produce optimum benefits. Education and training in detector use and escape practices may be necessary to achieve optimum loss reductions in the population as a whole.

- The significant potential for loss reduction when residential sprinklers are installed, particularly as new technology produces better systems at lower cost, warrants further attention. In particular the recently developed "fast response" sprinkler should be evaluated.

\section{Future Efforts}

- Further effort is necessary, and is underway, to improve the validity and credibility of the results presented here, and thus to improve the reliability of the decision making process. These efforts include the improvement and validation of data and assessments used for probability and loss assignments, the development of better information in key areas where results are sensitive to reasonable variations in assessments, the expansion of the models to allow for improved assessment techniques, the evaluation of additional alternatives, consideration of demographic and socio-economic factors, the development of detailed cost information, and the application of the methodology to other residential occupancies.

\section{REFERENCES}

[1] Highlights of Fire in the United States, Second Edition, U.S. Fire Administration, Federal Emergency Management Agency (April 1981).

[2] Helzer, S.G., Buchbinder, B., and Offensend, F.L., Decision Analysis of Strategies for Reducing Upholstered Furniture Fire Losses, National Bureau of Standards (U.S.), NBS TN 1101 (June 1979).

[3] NFPA 901, Uniform Coding for Fire Protection, National Fire Protection Association (1976).

[4] Gomberg, A., Evaluating the Impact of Detectors on Fire Fatalities in One and Two Family Dwellings, unpublished internal report, National Bureau of Standards (U.S.). 


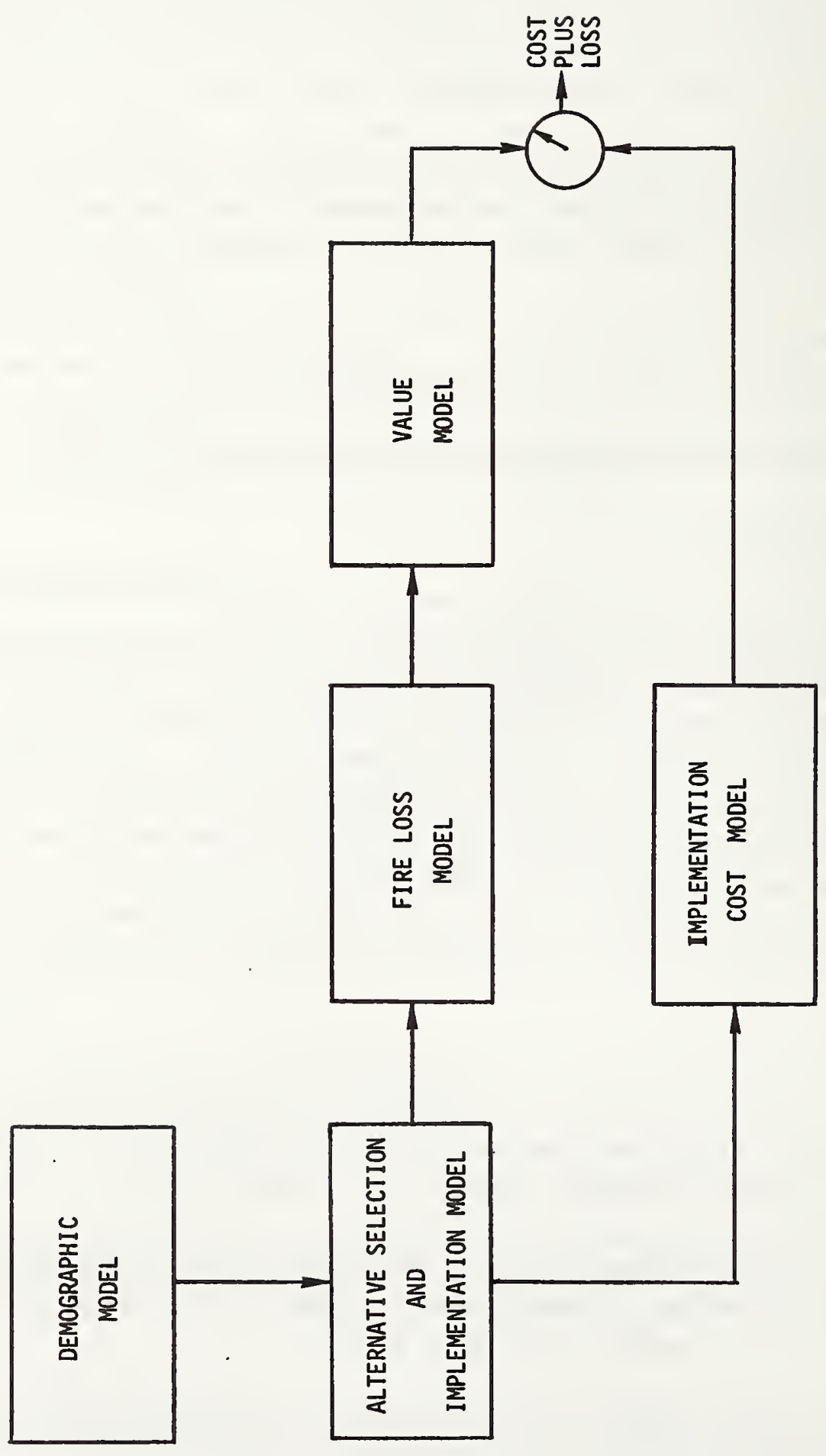

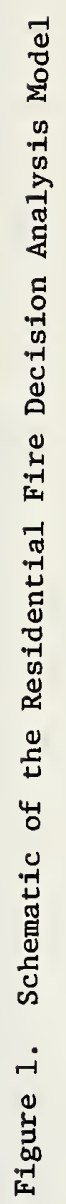




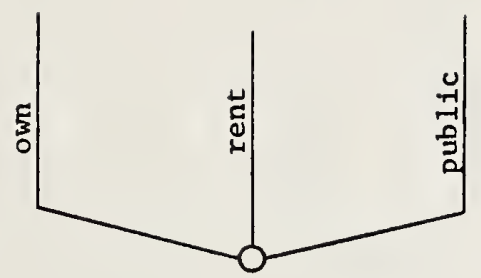

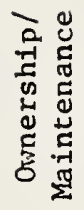
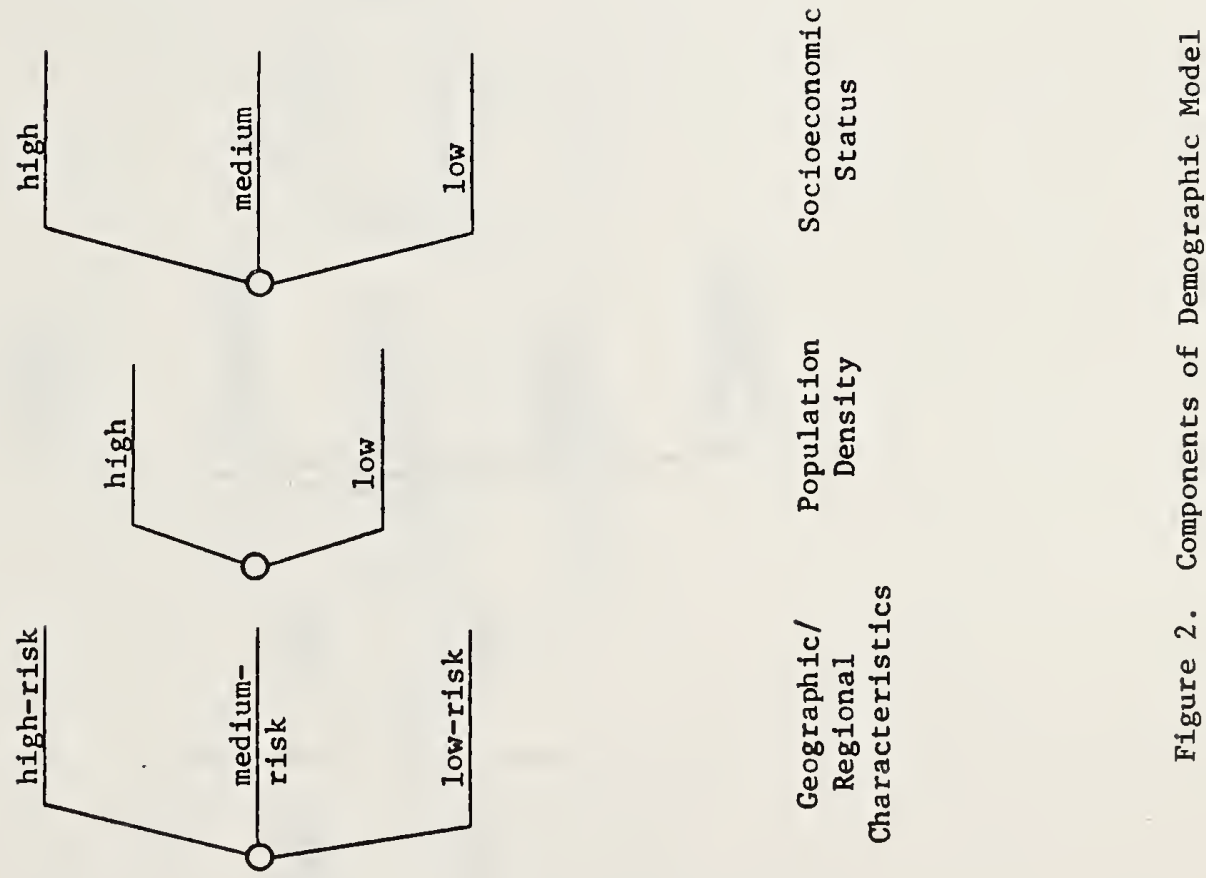

ن

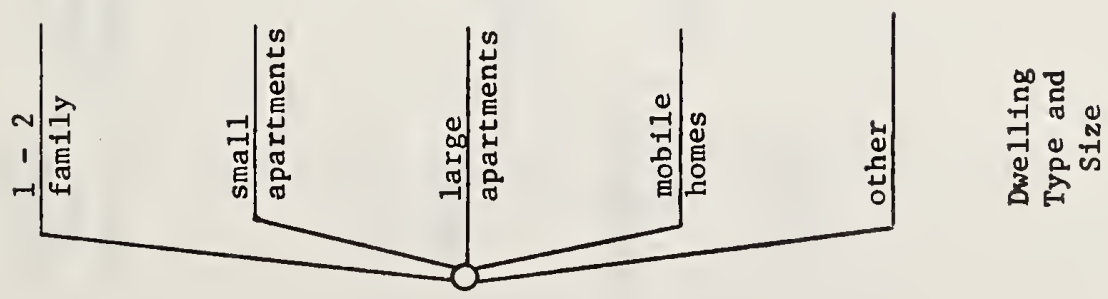




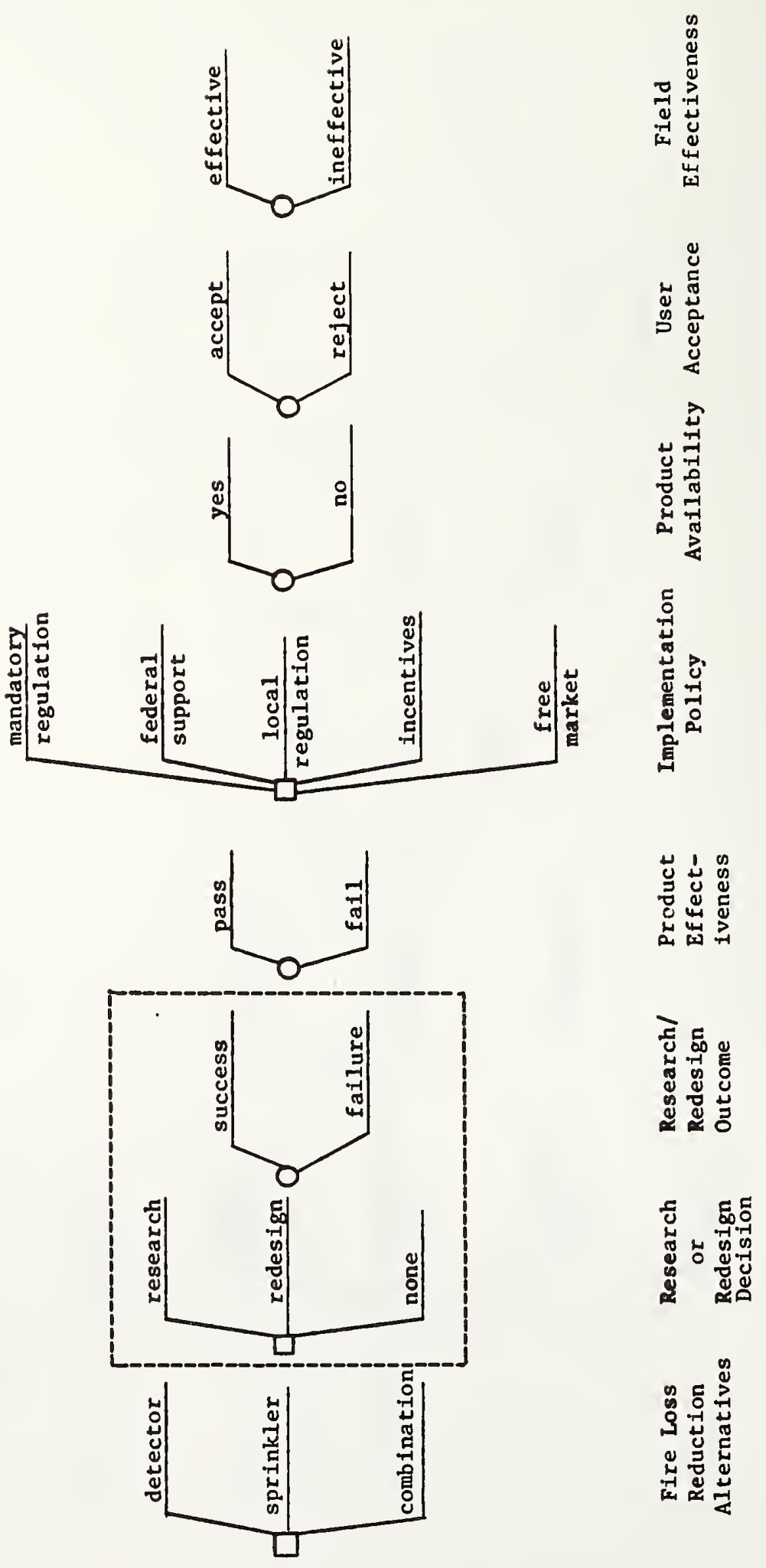



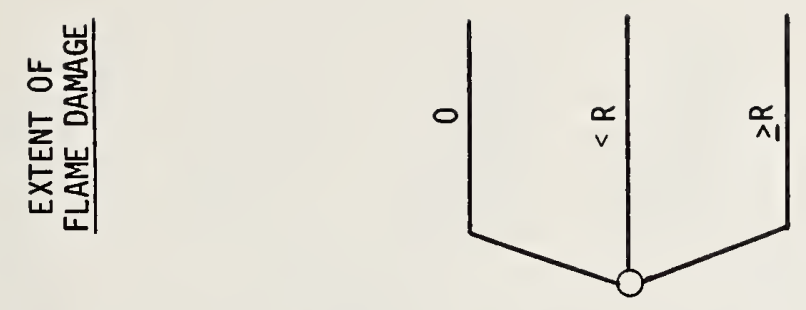

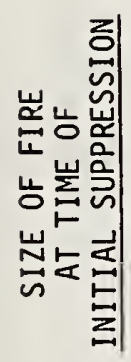

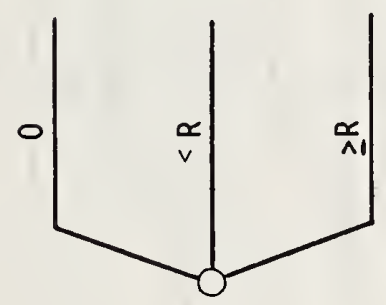

垔

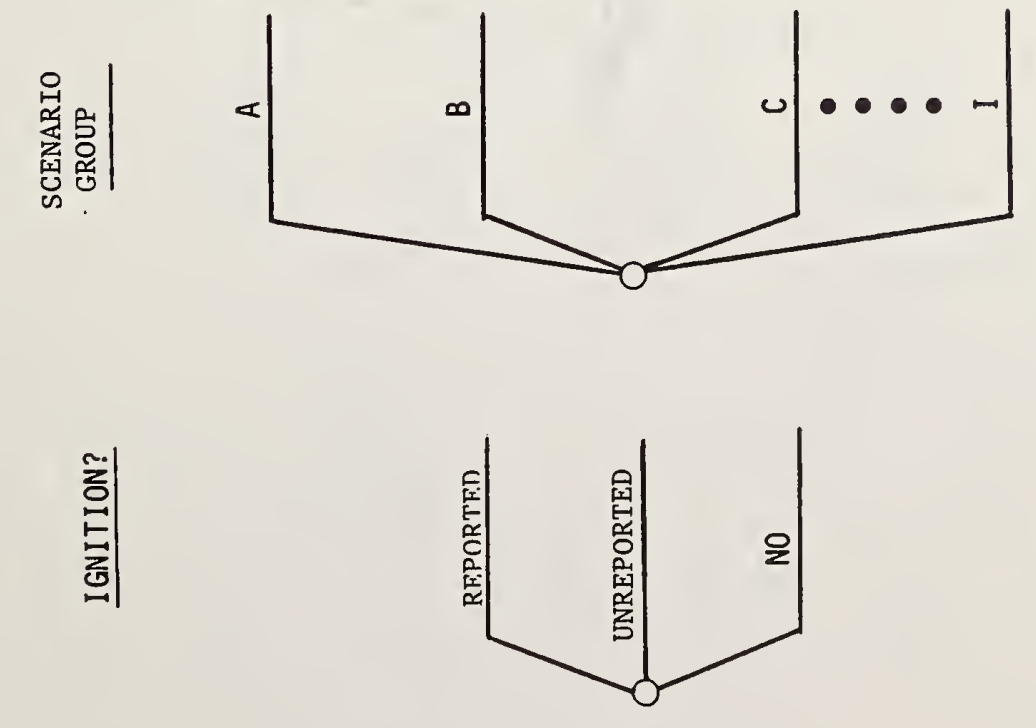

范

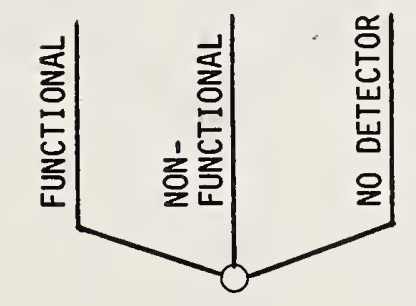

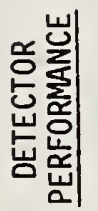




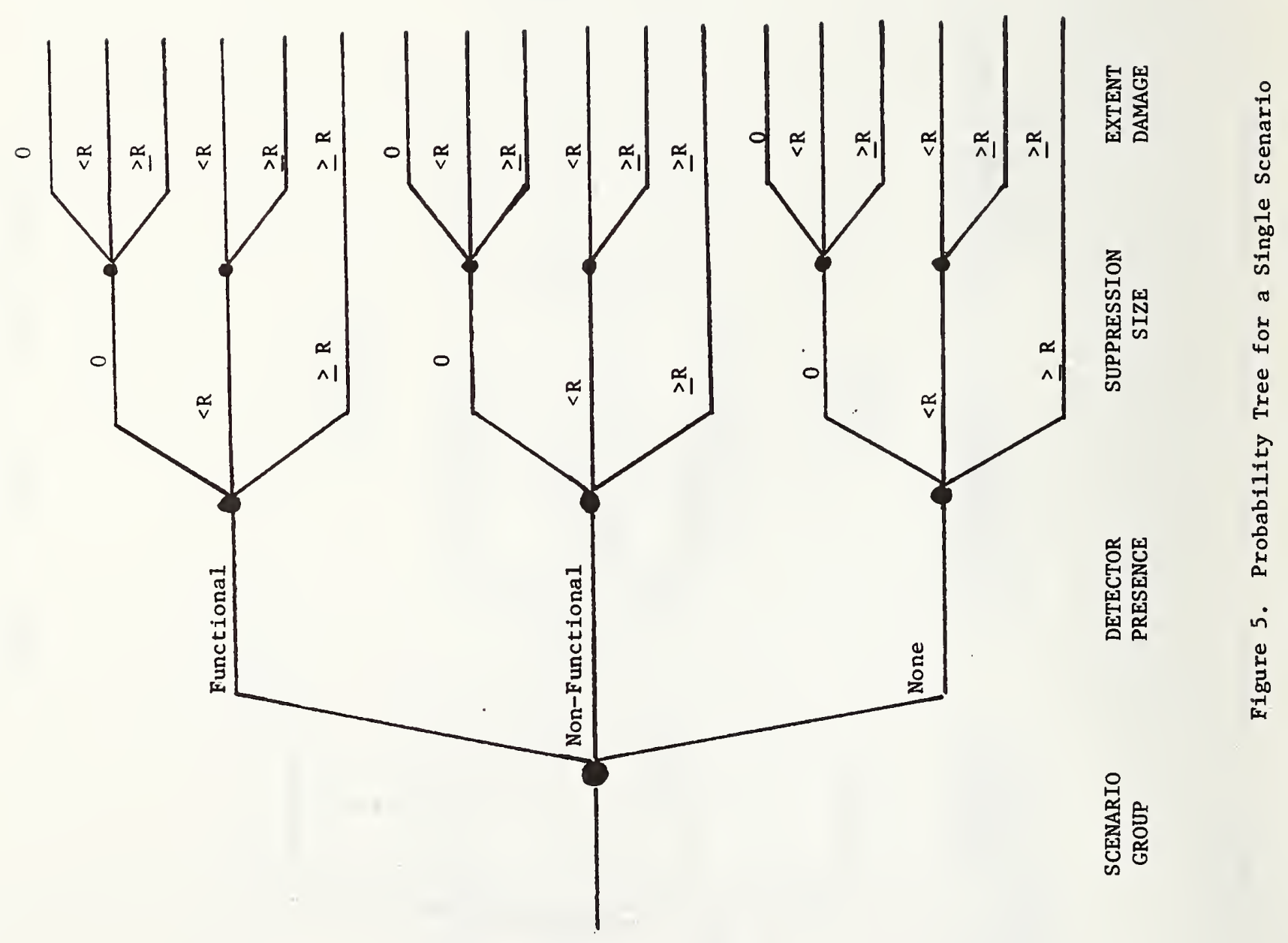




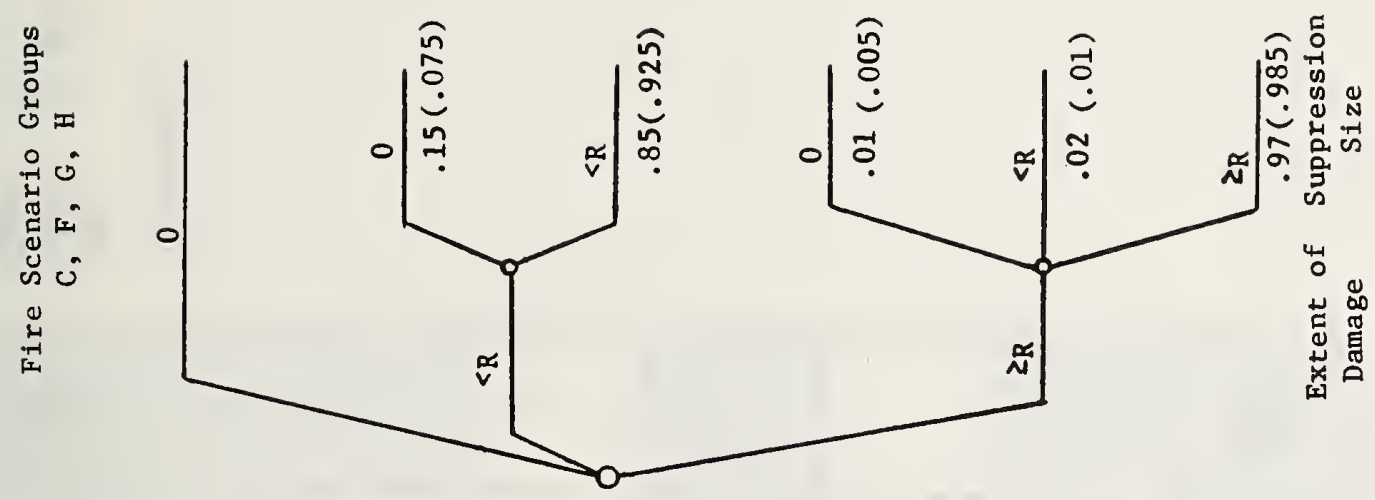

告

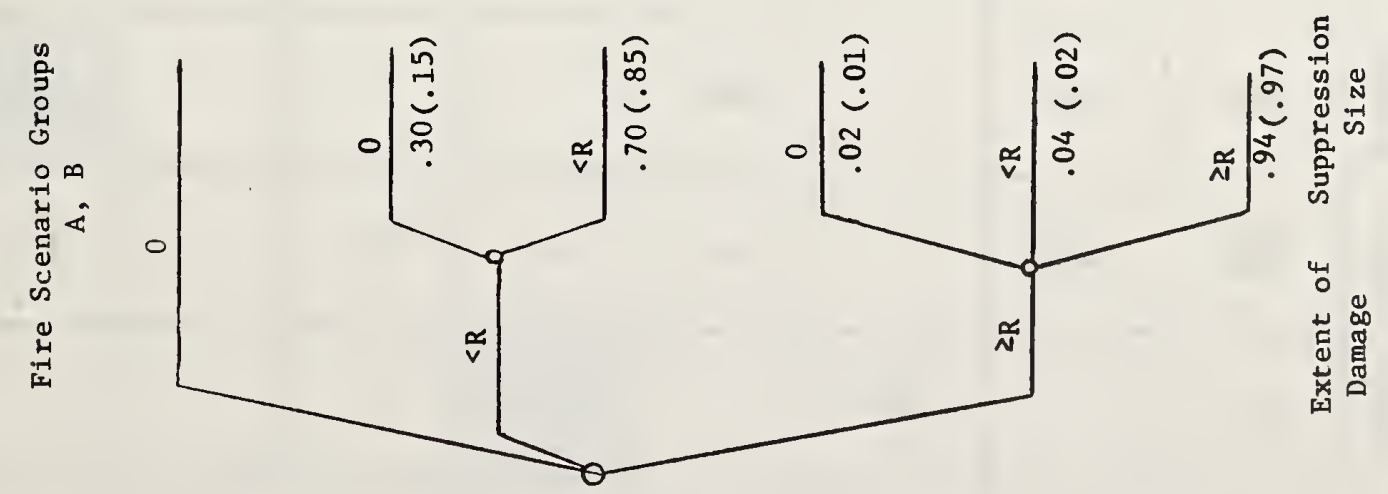




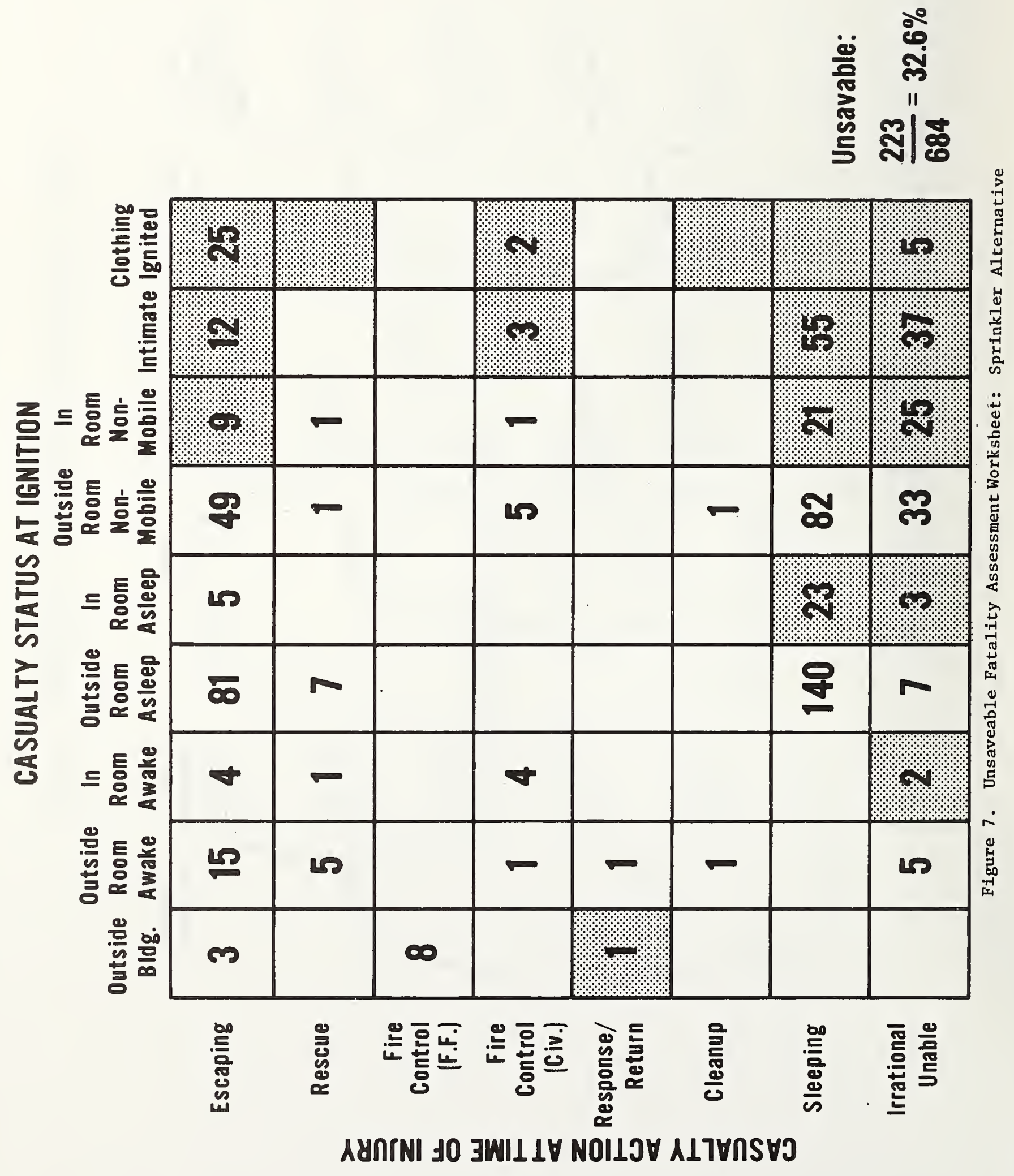




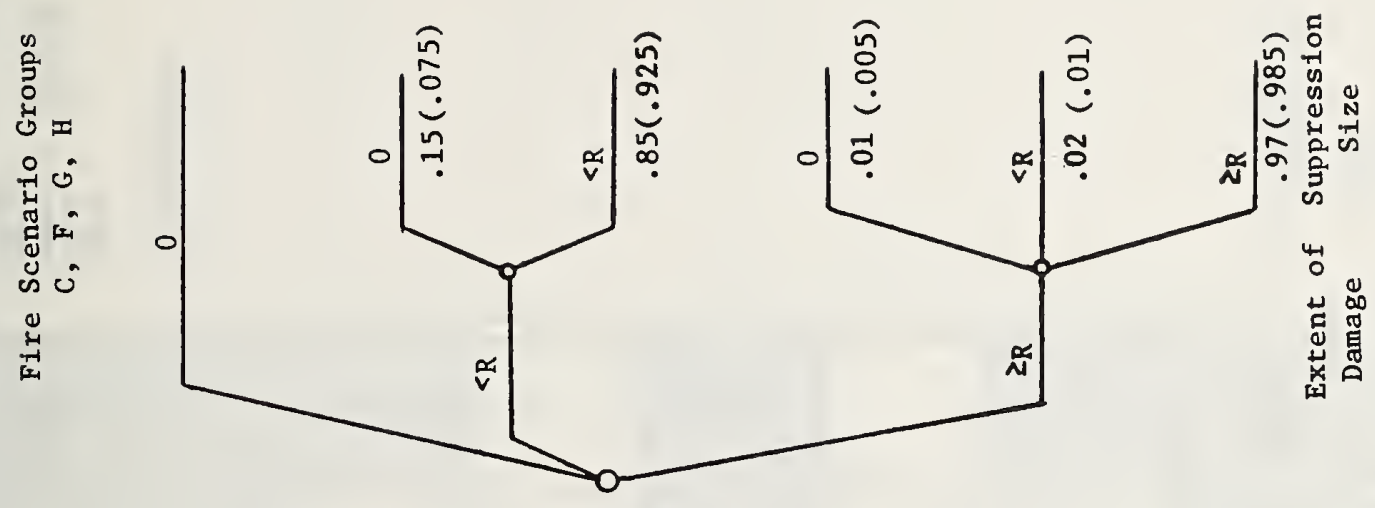

क्ष

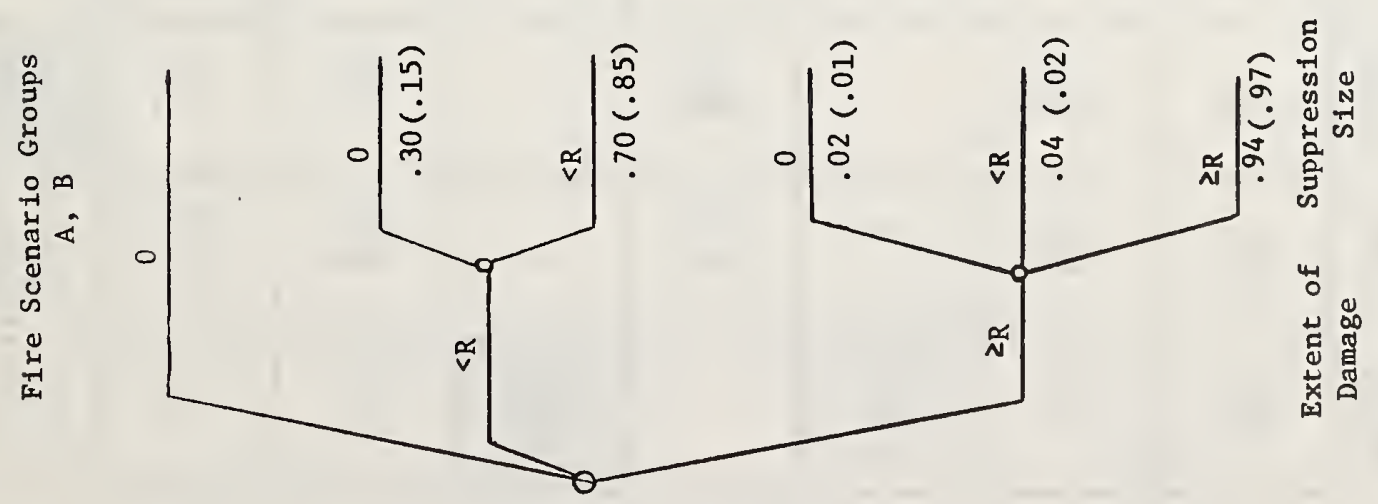




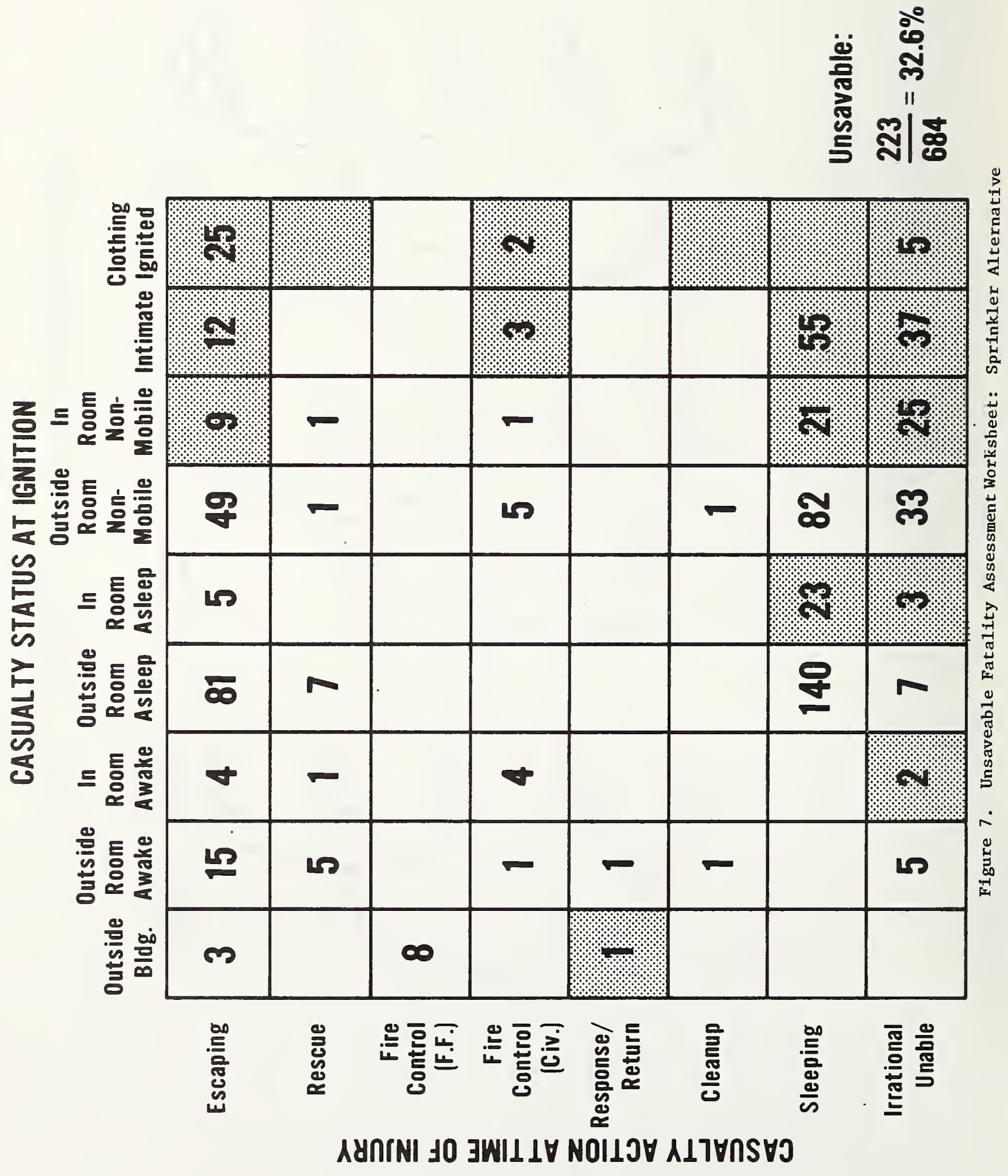




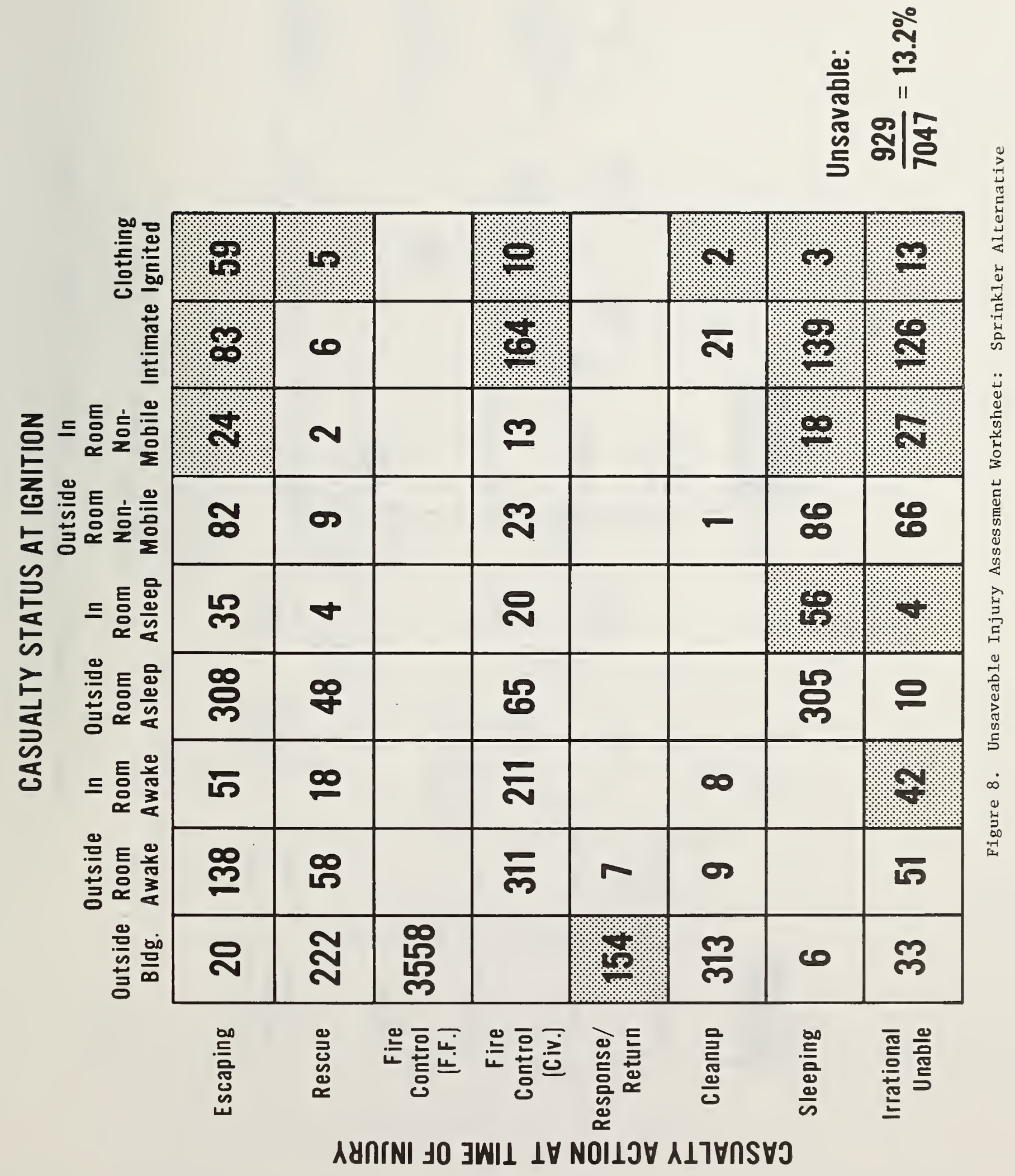




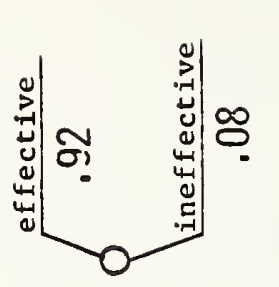

告

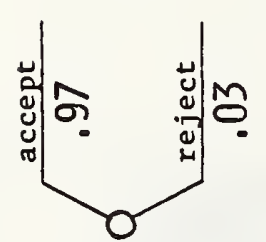

ș

章
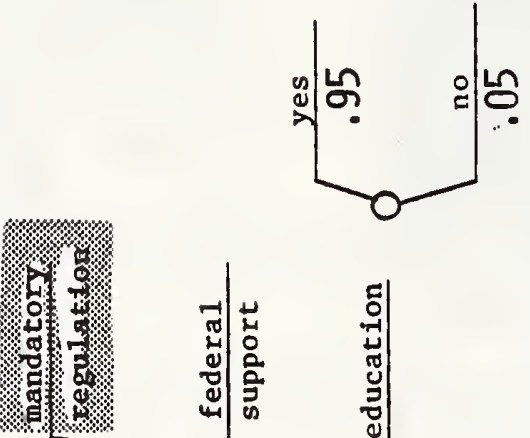

崩
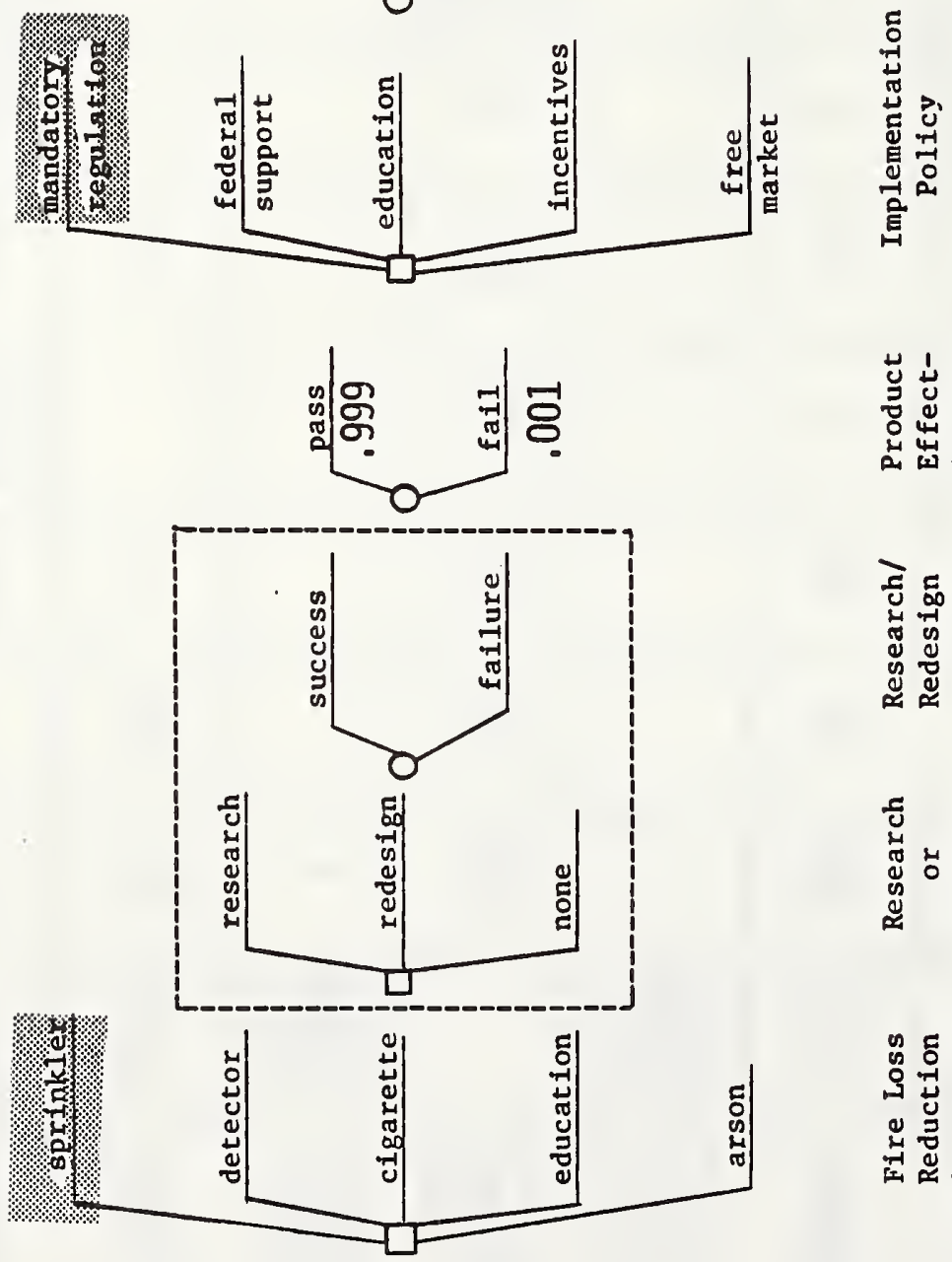

岂芫

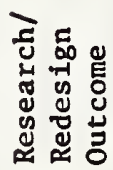

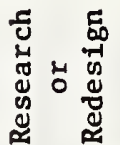

蒈

1

a 


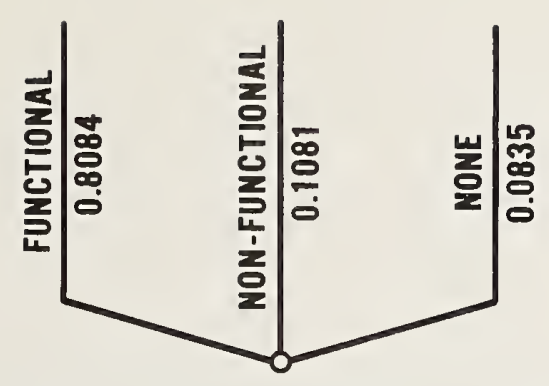

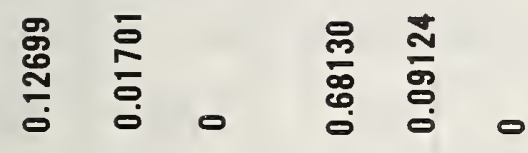

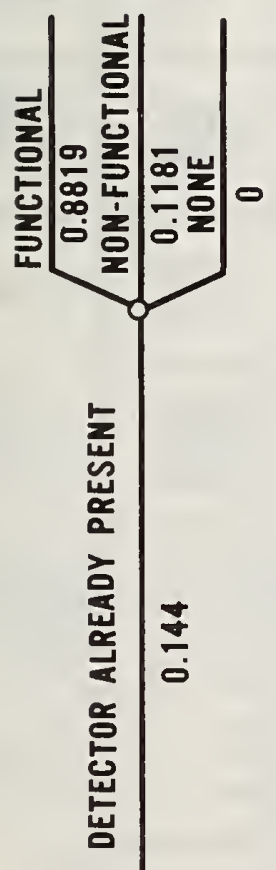

言

吕
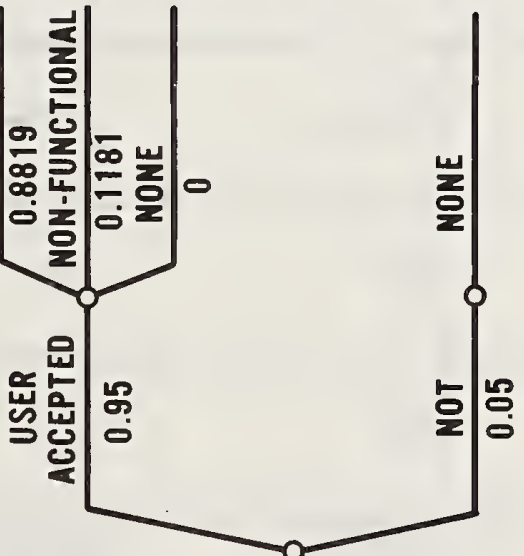


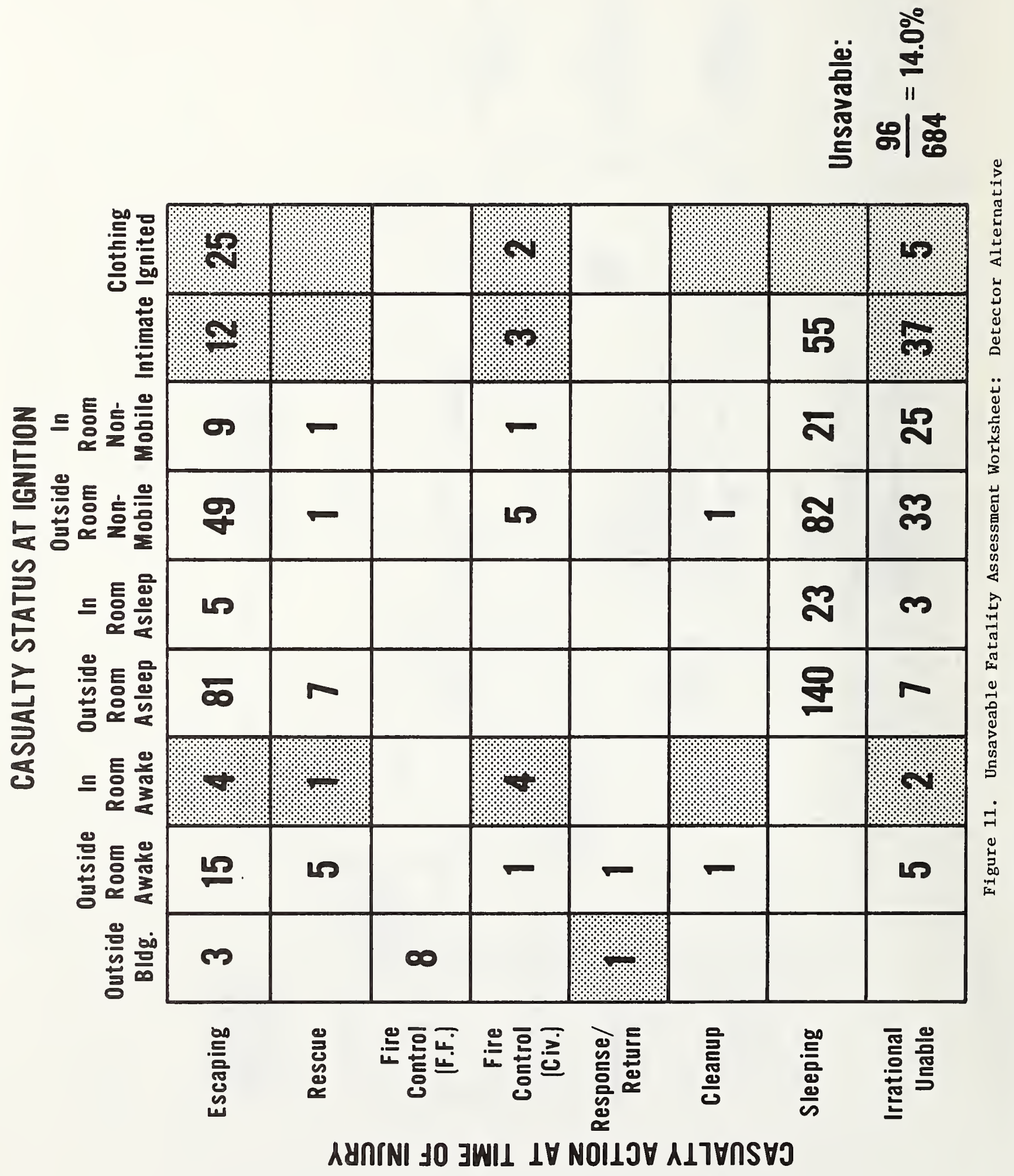




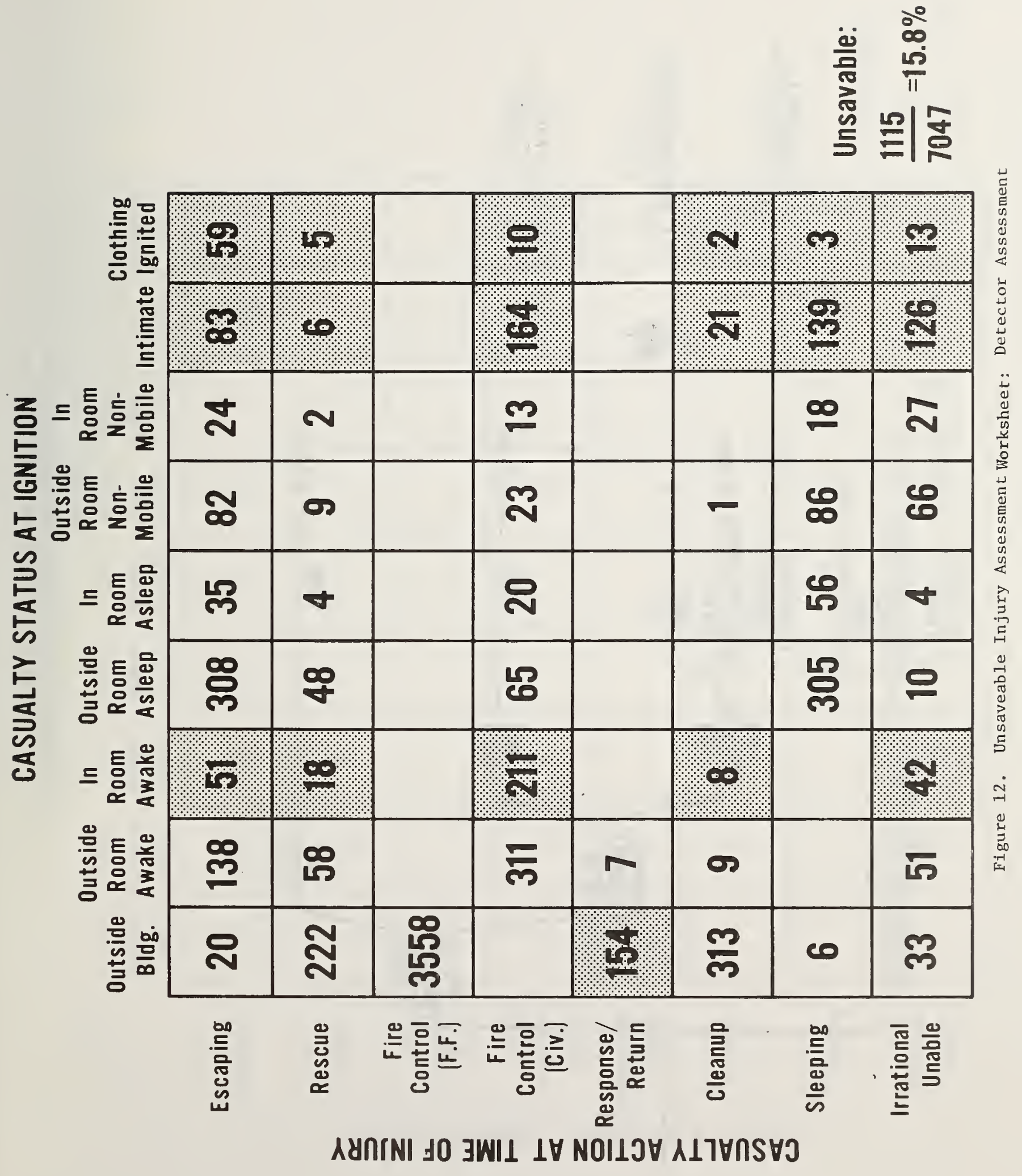




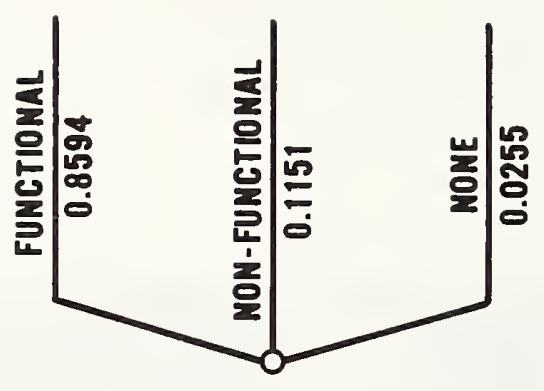

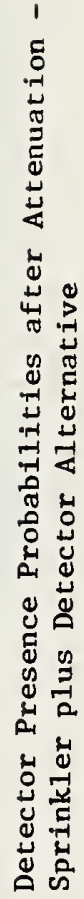

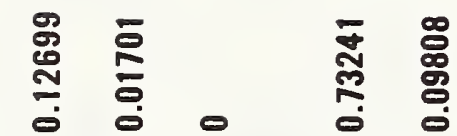

용

8
0
0
0

||

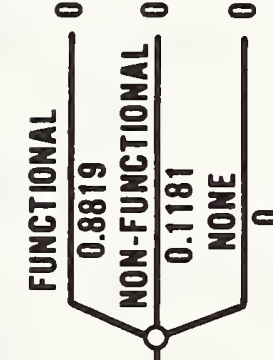

톤

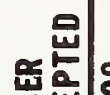

苗立

乌
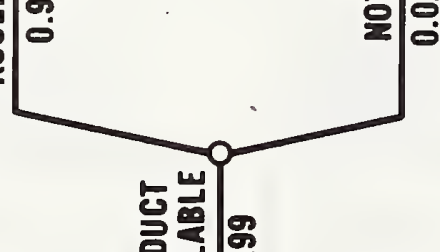

링

员

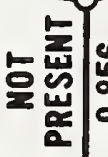




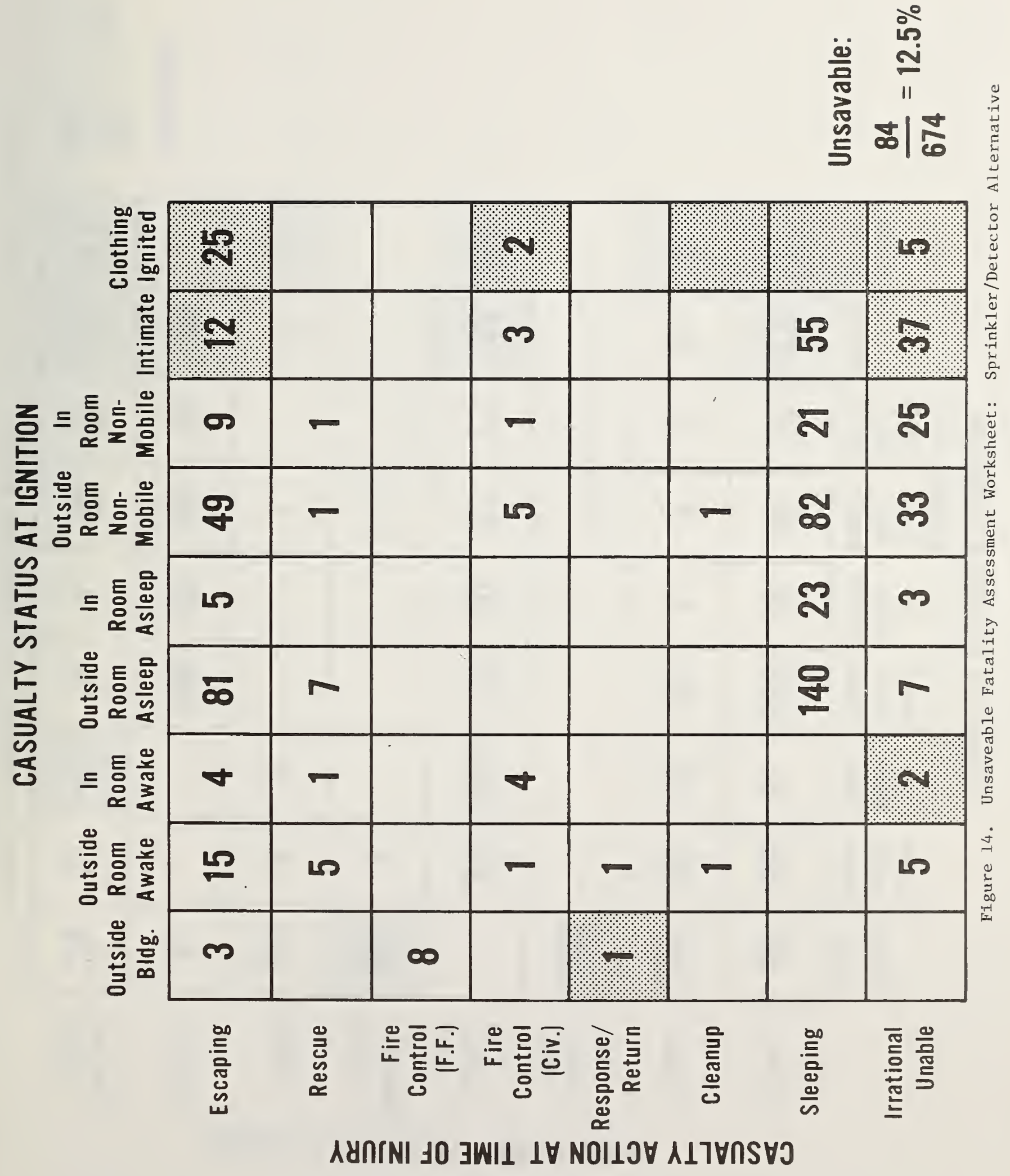




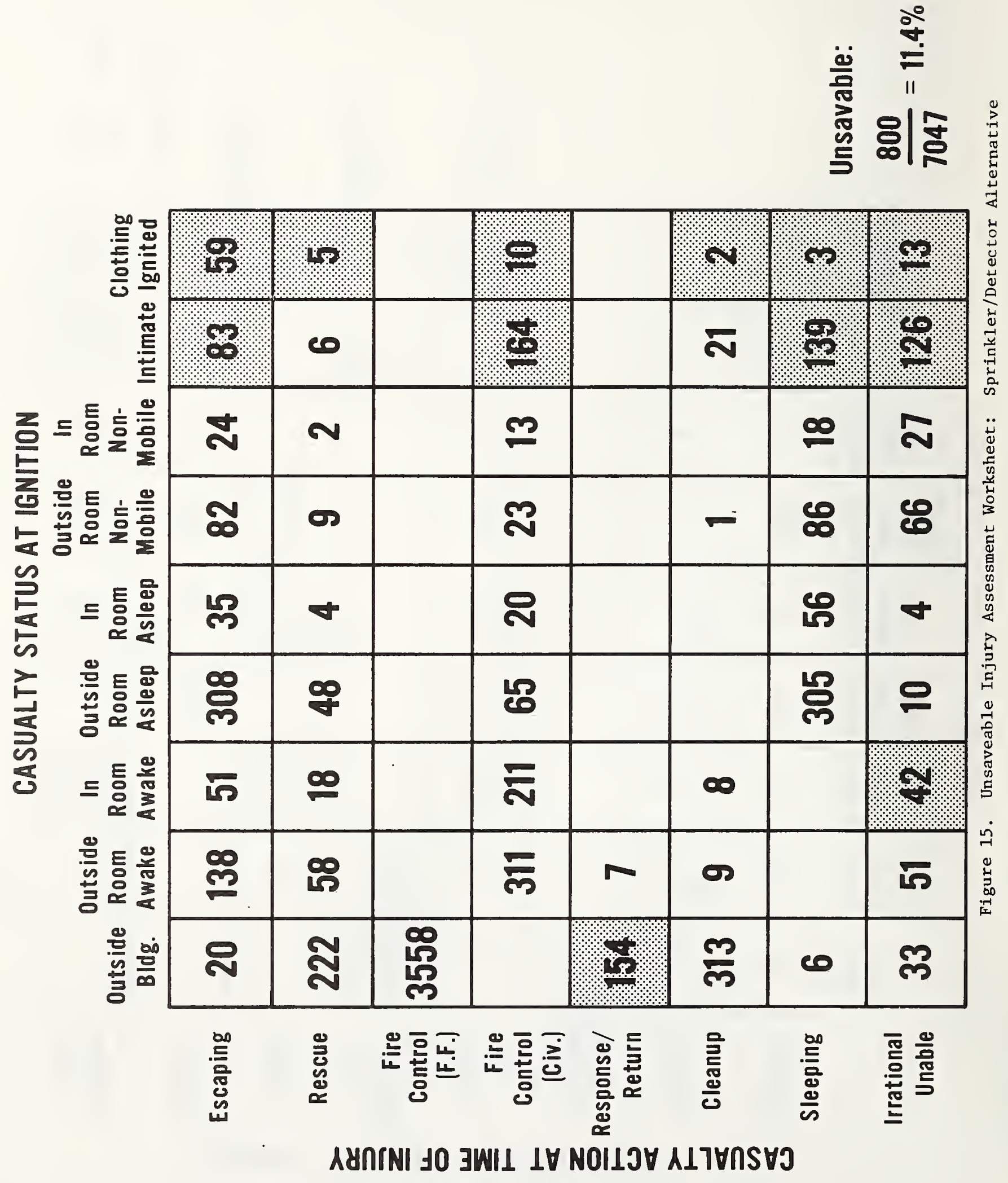



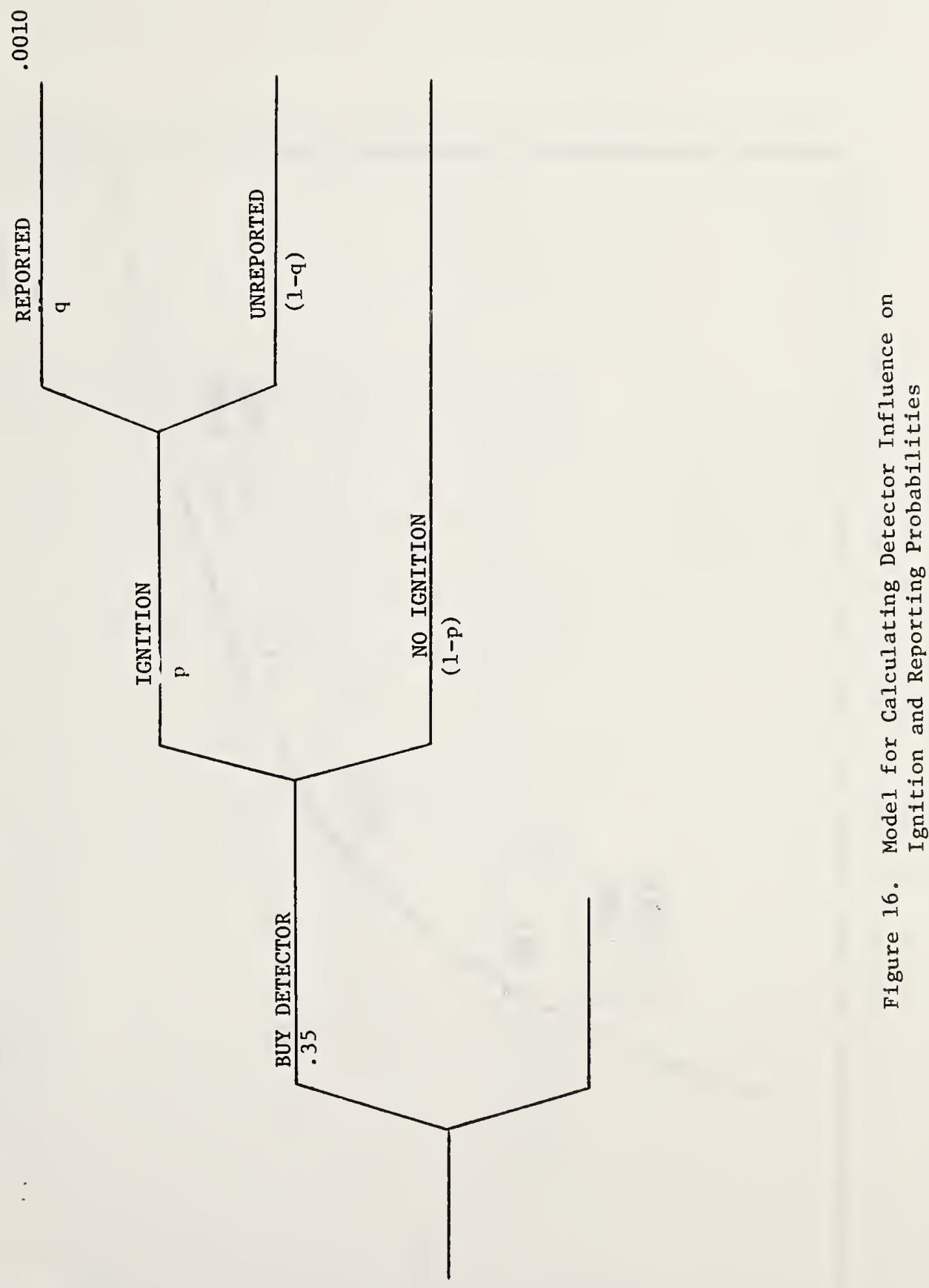


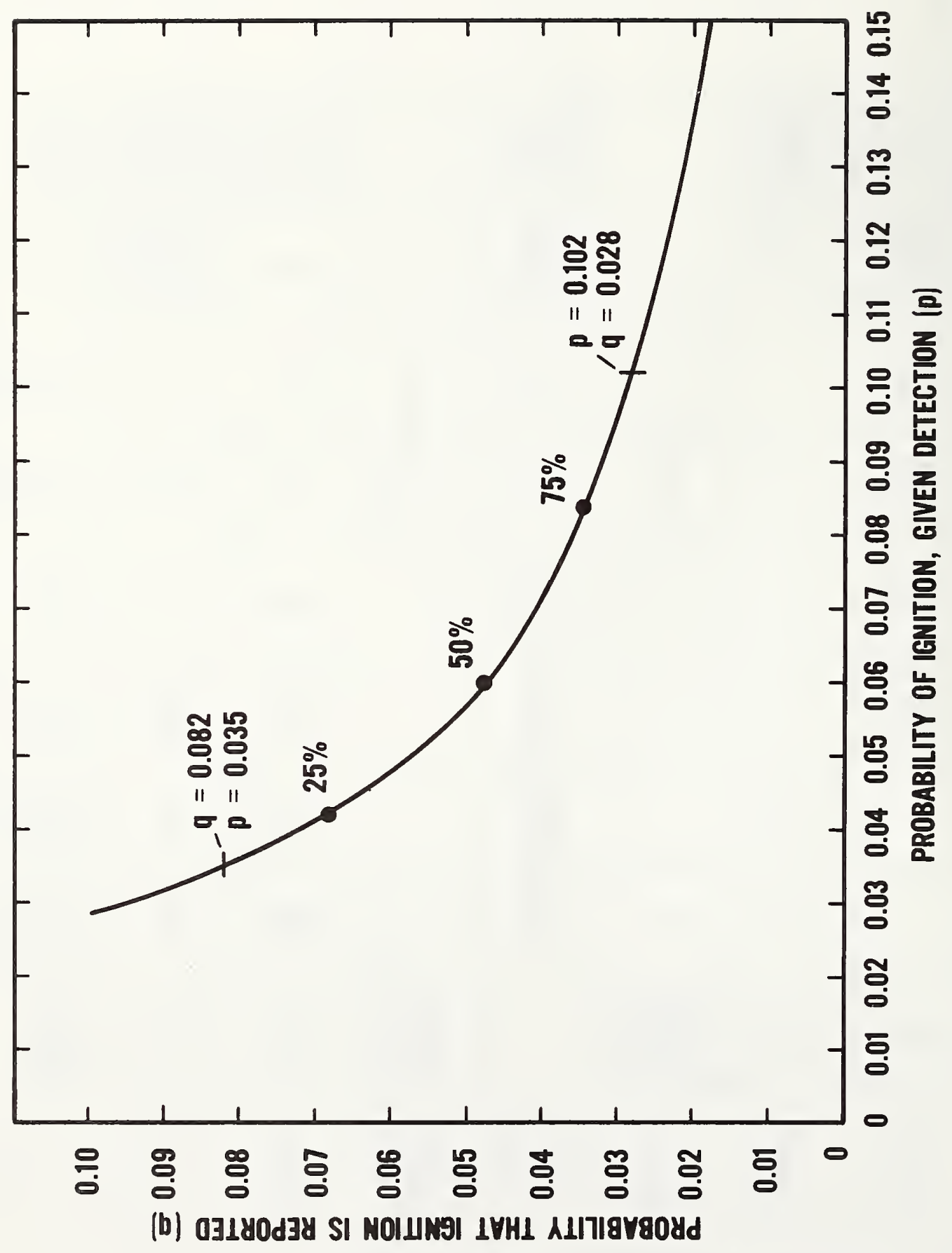

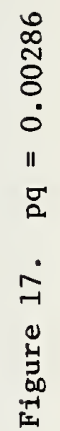




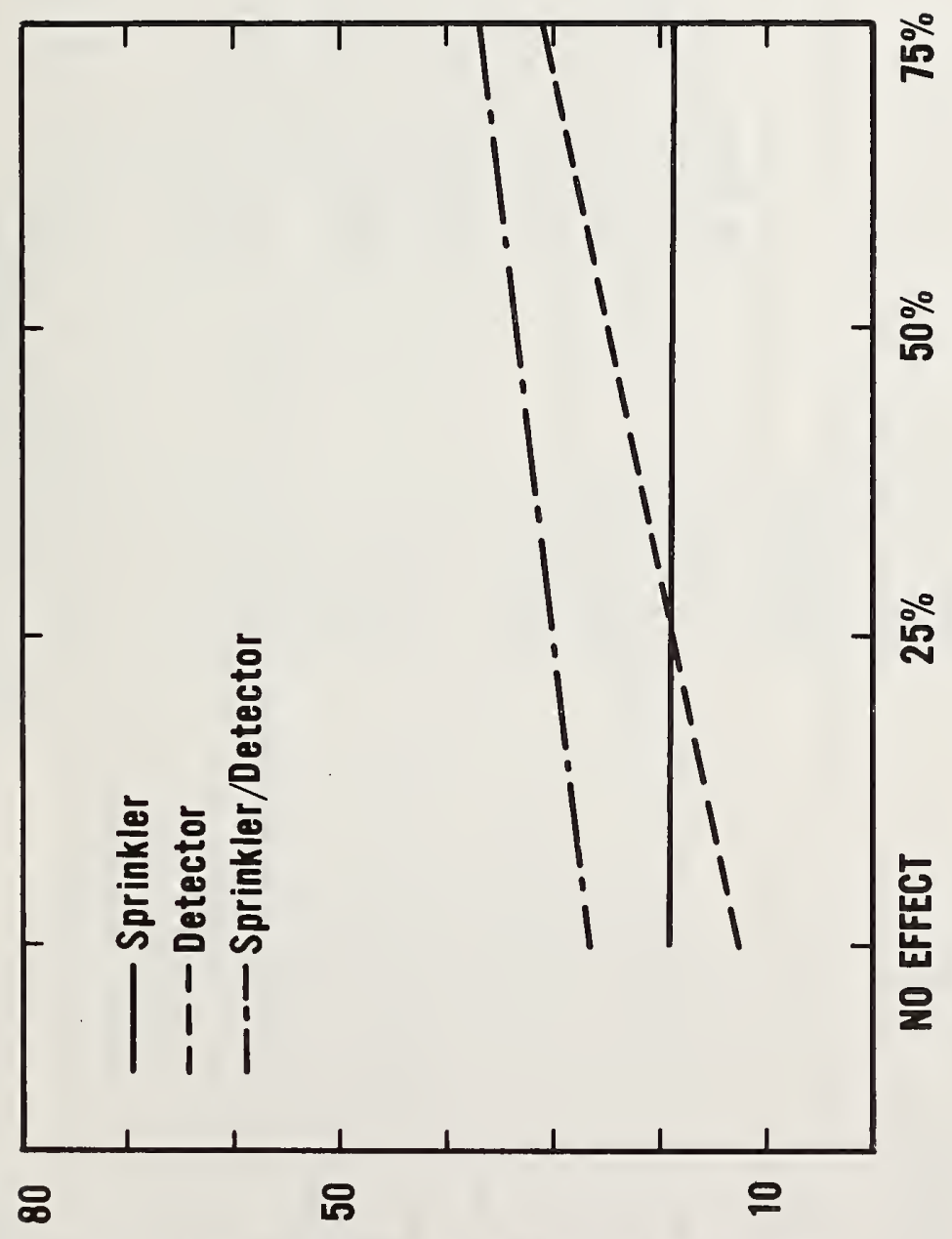

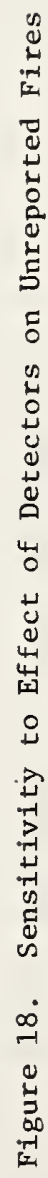

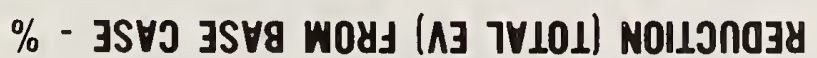




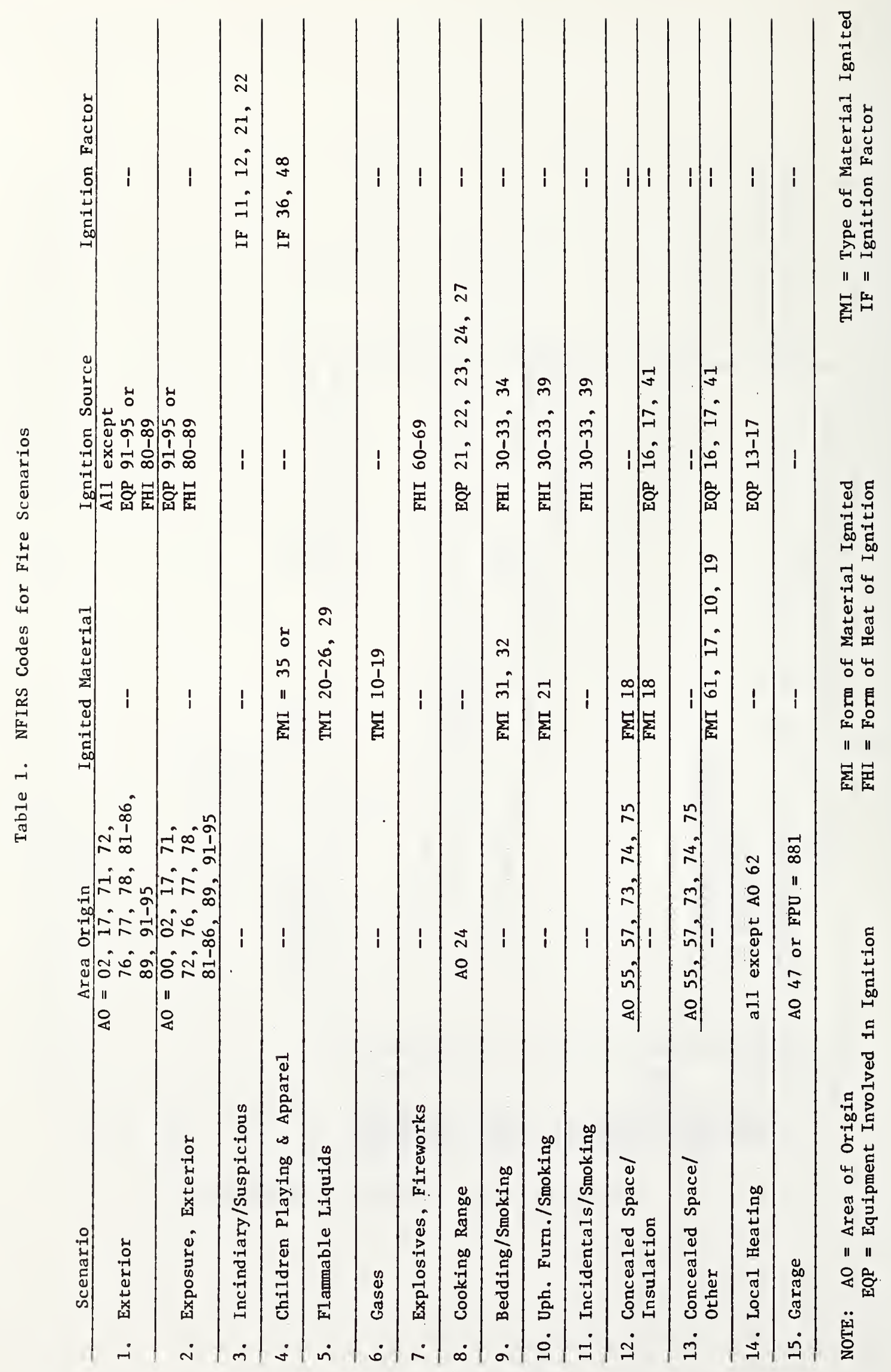




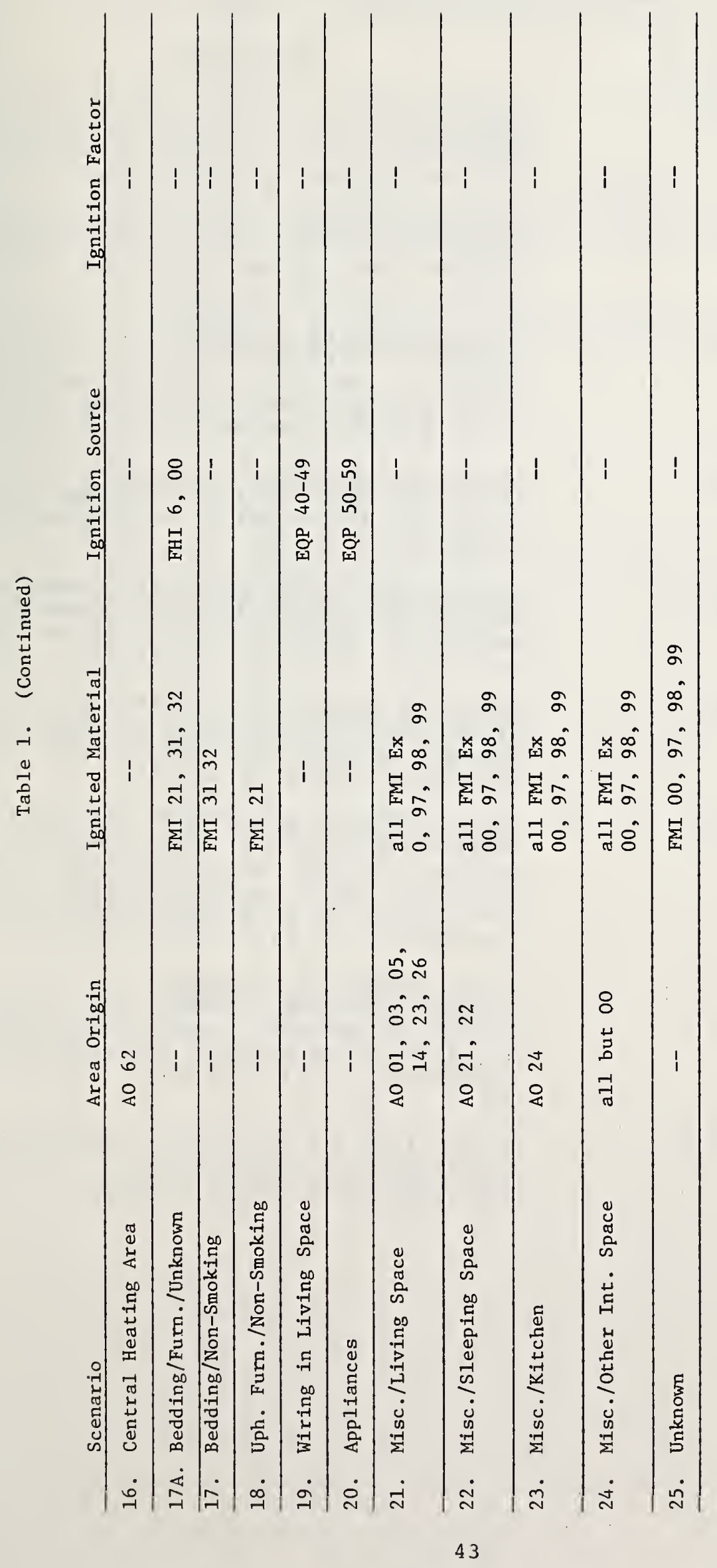


Table 2. Description of Fire Scenario Groups

SCENARIO GROUP

A

$\underline{\text { PROBABILITY }}$

.2139

B

.1169

C

D

E

F

G

$\mathrm{H}$

.1395

I

\section{DESCRIPTION}

Exterior fires, igniting roof or walls, on open porches, car fires in yard, brush and trash fires in yard, usually involving building eventually. (Scenarios 1,2 )

Rapidly Developing fires, either incendiary/ suspicious fires, or those where flammable liquids, gases or explosives are involved in ignition. (Scenarios $3,5,6,7$ )

Children Playing, Apparel fires, where clothing on a person is the first material ignited, or where the ignition results from children playing with the source of ignition or the material ignited. (Scenario 4)

Smoldering Upholstered Furniture fires are upholstered furniture, mattress and bedding fires ignited by smoking materials. (Scenarios $9,10,17 \mathrm{~A}$ )

Flaming Upholstered Furniture fires, where the upholstered furniture, mattress or bedding is ignited by other than smoking materials. (Scenarios $17,18,17 \mathrm{~A}$ )

Concealed space fires, primarily wiring within the walls and ceiling, ducts and chutes. Chimney fires are included in this category. (Scenarios 12,13 )

Interior Living Space fires are those not categorized above, in the living room, bedroom, kitchen, dining room and hallways. sprinklers and detectors are likely to be installed so as to protect these areas. (Scenarios $8,11,14,16,19,20,21,22,23$ )

Interior Non-Living Space fires are in closets, bathrooms, laundry and storage areas, and garages. Most of these areas would not be expected to have sprinklers or detectors installed in them. (Scenarios 15, 24)

Other fires are those that cannot be identified or categorized. This group is very small. (All other fire except unknown) 
Table 3. Detector Presence Probabilities*

State

Functional

Non-Functional

None
Description

In room of fire origin and operated.

Not in room of fire origin and operated. Fire too small to require operation.

In room of fire origin and did not operate. Not in room of fire origin and did not operate.

No detectors present.
Probability

.1267

.0174

.8559

*Note: These probabilities are conditional on reported fires, i.e., they are "given a reported fire". 


\section{Scenario Groups}

A

B

C

D

$\begin{aligned} E & \\ \quad & 0 \\ & \mathrm{R} \\ & \mathrm{R}\end{aligned}$

0
$<$
$R$

$\geq R$

0

$<\mathrm{R}$

$\geq \mathrm{R}$

$\begin{array}{r}0 \\ <\mathrm{R} \\ \hline\end{array}$

$\geq \mathrm{R}$

0

$<\mathrm{R}$

$\geq \mathrm{R}$

$\geq \mathrm{R}$
Suppression Size

$\mathrm{F}, \mathrm{H}$

$<\mathrm{R}$

$\geq R$

G, I $\quad<\quad$ R

$\geq \mathrm{R}$
Change to Probability for Sprinkler Alternative

No change

Add $25 \%$ of $\geq R$ probability to < R Reduce $\geq R$ probability by $25 \%$

Add $30 \%$ of $\geq R$ probability to 0 Add 508 of $>R$ probability to < R Reduce $\geq R$ probability by $80 \%$

Add 208 of $\geq R$ probability to 0 Add $80 \%$ of $\gg R$ probability to $<R$ Reduce $\geq \mathrm{R}$ probability by $100 \%$

Add 808 of $>$ R probability to 0 Add $20 \%$ of $>R$ probability to $<R$ Reduce $\geq R$ probability by $100 \%$

Add 608 of $\geq R$ probability to 0 Add $40 \%$ of $\geq R$ probability to < R Reduce $\geq R$ probability by $100 \%$

No change

Add $30 \%$ of $>R$ probability to $<R$ Reduce $\geq R$ probability by $30 \%$

Add $10 \%$ of $>$ R probability to 0 Add $90 \%$ of $\sum R$ probability to < R Reduce $\geq \mathrm{R}$ probability by 1008 
Table 5. Nominal Loss Reductions for Three Alternatives

Possible Reduction* in
Fatality Rate Injury Rate Property Loss

Sprinkler Alternative ${ }^{1}$

Detector Alternative ${ }^{2}$

Sprinkler/Detector Alternative ${ }^{1}$
$34 \%$

$41 \%$

$58 \%$
$17 \%$

48

$18 ㅇ$
38 웋

$16 \%$

$46 \%$

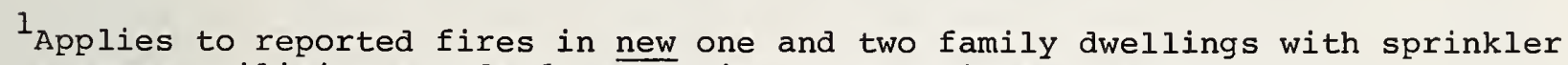
systems utilizing standard commercial type sprinkler heads only.

${ }^{2}$ Applies to reported fires in all one and two family dwellings.

*The results presented here indicate current estimates of possible reductions in fatality, injury and property loss rates under the three alternatives considered. The estimates also include modeling of the attenuation previously described in the alternative selection and implementation model. It is important to regard these results in the context of the specific definitions and scope of the alternatives considered as well as the implementation strategy defined for each. Additional work, including more detailed modeling and further evaluation of assessments, as indicated by sensitivity testing, is necessary to refine and substantiate these estimates, and to allow for the evaluation of additional alternatives. 


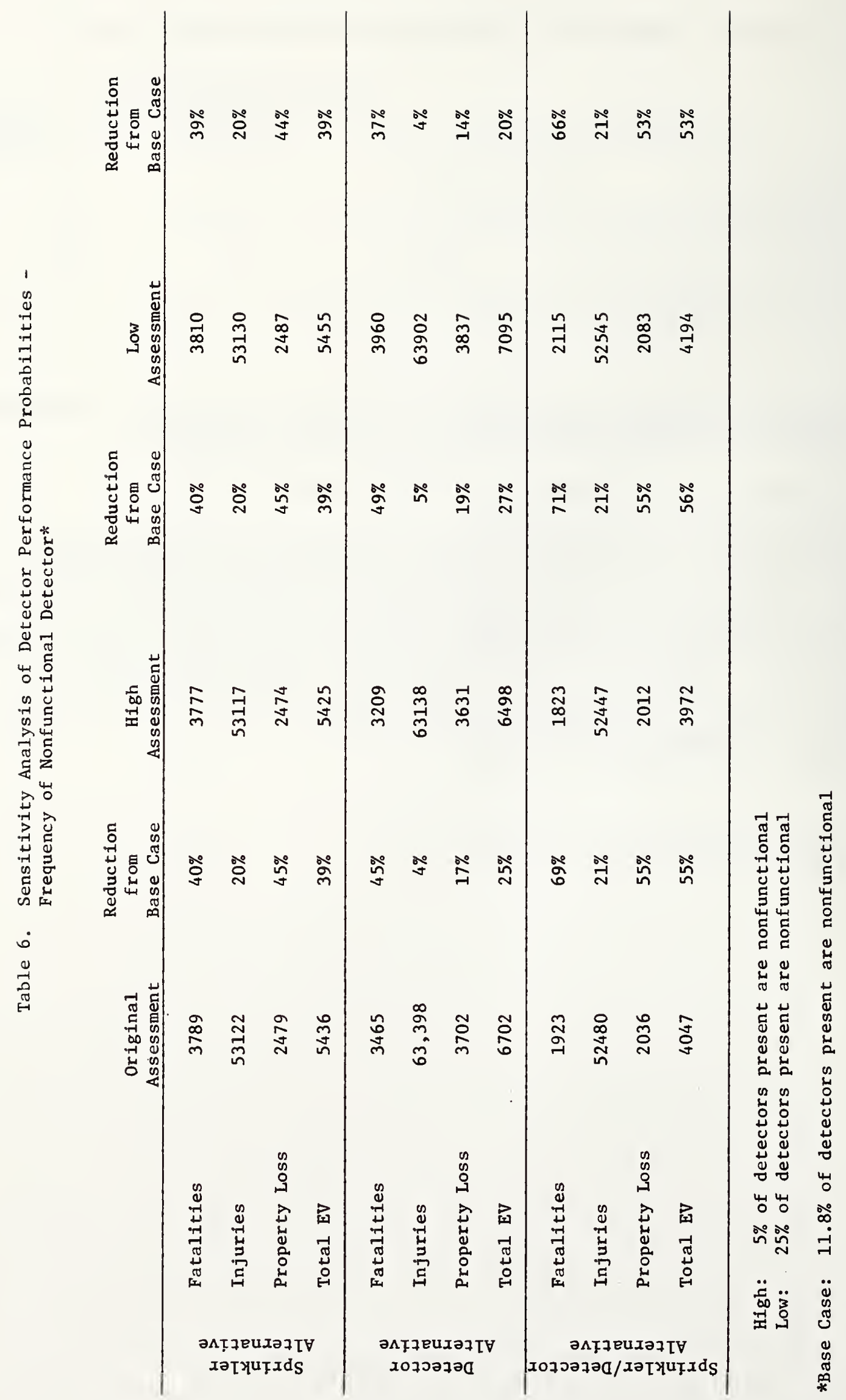




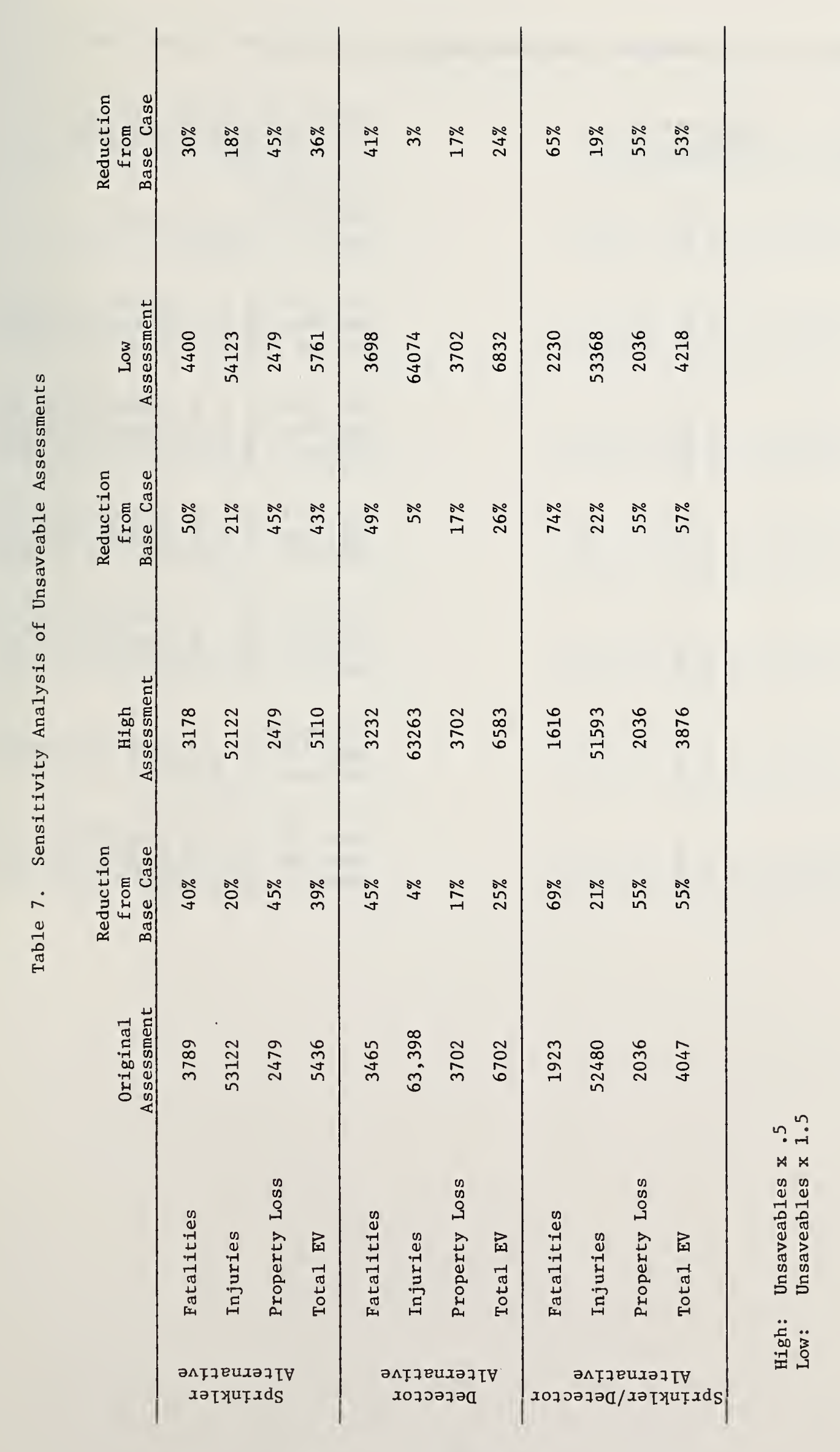


Table 8. Suppression Size Assessments - Sprinkler Alternative

Scenario

Groups

A

Suppression

Size

0

$<\mathrm{R}$

$\geq R$

B

$\quad 0$
$<\quad R$
$\geq$

C

$$
\begin{array}{r}
0 \\
<\quad R \\
\geq R
\end{array}
$$

D

$$
\begin{array}{r}
\quad \\
<\quad R \\
\geq R
\end{array}
$$

E

$$
\begin{aligned}
& \begin{array}{r}
0 \\
<\quad R
\end{array} \\
& \begin{array}{l}
<\mathrm{R} \\
\geq \mathrm{R}
\end{array}
\end{aligned}
$$

$\begin{aligned} \mathrm{F}, \mathrm{H} \quad & 0 \\ & <\mathrm{R} \\ & \geq \mathrm{R}\end{aligned}$

$\begin{array}{ll}\mathrm{G}, \mathrm{I} & \\ & \\ & \\ & \mathrm{R} \\ & \geq \mathrm{R}\end{array}$

Change to Probability for Sprinkler Alternative

No change

Add $25 \%$ of $>$ R probability to $<R$ Reduce $\geq$ probability by $25 \%$

Add $30 \%$ of $\geq R$ probability to 0 Add $50 \%$ of $\geq R$ probability to < R Reduce $\geq R$ probability by $80 \%$

Add $20 \%$ of $\geq R$ probability to 0 Add $80 \%$ of $\geq R$ probability to $<R$ Reduce $\geq \mathrm{R}$ probability by $100 \%$

Add $80 \%$ of $\geq R$ probability to 0 Add $20 \%$ of $\geq R$ probability to $<R$ Reduce $\geq \mathrm{R}$ probability by $100 \%$

Add $60 \%$ of $>R$ probability to 0 Add $40 \%$ of $\geq R$ probability to $<R$ Reduce $\geq R$ probability by $100 \%$

No change

Add 308 of $>$ R probability to $<R$ Reduce $\geq R$ probability by $30 \%$

Add 108 of $\geq \mathrm{R}$ probability to 0 Add 908 of $\geq R$ probability to $<R$ Reduce $\geq R$ probability by $100 \%$ 
Table 9. High Suppression Size Assessments - Sprinkler Alternative

\begin{tabular}{|c|c|}
\hline $\begin{array}{l}\text { Scenario } \\
\text { Groups }\end{array}$ & $\begin{array}{l}\text { Suppression } \\
\text { Size } \\
\end{array}$ \\
\hline A & $\begin{aligned} & 0 \\
< & R \\
\geq & R\end{aligned}$ \\
\hline B & $\begin{aligned} & 0 \\
< & R \\
\geq & R\end{aligned}$ \\
\hline c & $\begin{aligned} & 0 \\
< & R \\
\geq & R\end{aligned}$ \\
\hline D & $\begin{aligned} & 0 \\
< & R \\
\geq & R\end{aligned}$ \\
\hline$E$ & $\begin{aligned} & 0 \\
< & R \\
\geq & R\end{aligned}$ \\
\hline $\mathrm{F}, \mathrm{H}$ & $\begin{aligned} & 0 \\
< & R \\
\geq & R\end{aligned}$ \\
\hline$G, I$ & $\begin{aligned} & 0 \\
< & R \\
\geq & R\end{aligned}$ \\
\hline
\end{tabular}

Change to Probability for
Sprinkler Alternative

Add $25 \%$ of $\geq R$ probability to 0 Add $25 \%$ of $\ R$ probability to $<R$ Reduce $\geq$ R probability by $50 \%$

Add 25\% of $\geq R$ probability to 0 Add $70 \%$ of $>$ R probability to $<R$ Reduce $\geq R$ probability by $95 \%$

Add $60 \%$ of $>\mathrm{R}$ probability to 0 Add $40 \%$ of $>R$ probability to $<R$ Reduce $\geq R$ probability by $100 \%$

Add $90 \%$ of $\geq R$ probability to 0 Add $10 \%$ of $>R$ probability to $<R$ Reduce $\geq \mathrm{R}$ probability by $100 \%$

Add $80 \%$ of $>$ R probability to 0 Add $20 \%$ of $\geq$ R probability to $<R$ Reduce $\geq \mathrm{R}$ probability by $100 \%$

Add $40 \%$ of $>$ R probability to 0 Add $10 \%$ of $>\mathrm{R}$ probability to $<\mathrm{R}$ Reduce $\geq R$ probability by $50 \%$

Add $50 \%$ of $\geq R$ probability to 0 Add $50 \%$ of $>\mathrm{R}$ probability to $<\mathrm{R}$ Reduce $\geq \mathrm{R}$ probability by $100 \%$ 
Table 10. Low Suppression Size Assessments - Sprinkler Alternative

\begin{tabular}{|c|c|c|}
\hline $\begin{array}{l}\text { Scenario } \\
\text { Groups }\end{array}$ & $\begin{array}{l}\text { Suppression } \\
\text { Size }\end{array}$ & $\begin{array}{l}\text { Change to Probability for } \\
\text { Sprinkler Alternative } \\
\end{array}$ \\
\hline A & $\begin{aligned} & 0 \\
< & R \\
\geq & R\end{aligned}$ & $\begin{array}{l}\text { No change } \\
\text { Add } 10 \% \text { of } \geq R \text { probabilities to }<R \\
\text { Reduce } \geq R \text { probability by } 108\end{array}$ \\
\hline B & $\begin{aligned} & 0 \\
< & R \\
\geq & R\end{aligned}$ & $\begin{array}{l}\text { Add } 10 \% \text { of } \geq R \text { probability to } 0 \\
\text { Add } 50 \% \text { of } \geq R \text { probability to }<R \\
\text { Reduce } \geq R \text { probability by } 60 \%\end{array}$ \\
\hline C & $\begin{aligned} & 0 \\
< & R \\
\geq & R\end{aligned}$ & $\begin{array}{l}\text { No change } \\
\text { Add } 80 \% \text { of } \geq R \text { probability to }<R \\
\text { Reduce } \geq R \text { probability by } 80 \%\end{array}$ \\
\hline D & $\begin{aligned} & 0 \\
< & R \\
\geq & R\end{aligned}$ & $\begin{array}{l}\text { Add } 60 \% \text { of } \geq R \text { probability to } 0 \\
\text { Add } 20 \% \text { of } \geq R \text { probability to }<R \\
\text { Reduce } \geq R \text { probability by } 80 \%\end{array}$ \\
\hline $\mathbf{E}$ & $\begin{aligned} & 0 \\
< & R \\
\geq & R\end{aligned}$ & $\begin{array}{l}\text { Add } 40 \% \text { of } \geq R \text { probability to } 0 \\
\text { Add } 40 \% \text { of } \geq R \text { probability to }<R \\
\text { Reduce } \geq R \text { probability by } 80 \%\end{array}$ \\
\hline $\mathrm{F}, \mathrm{H}$ & $\begin{aligned} & 0 \\
< & R \\
\geq & R\end{aligned}$ & $\begin{array}{l}\text { No change } \\
\text { Add } 108 \text { of } \geq R \text { probability to }<R \\
\text { Reduce } \geq R \text { probability by } 108\end{array}$ \\
\hline$G, I$ & $\begin{aligned} & 0 \\
< & R \\
\geq & R\end{aligned}$ & $\begin{array}{l}\text { Add } 108 \text { of } \geq R \text { probability to } 0 \\
\text { Add } 708 \text { of } \geq R \text { probability to }<R \\
\text { Reduce } \geq R \text { probability by } 808\end{array}$ \\
\hline
\end{tabular}




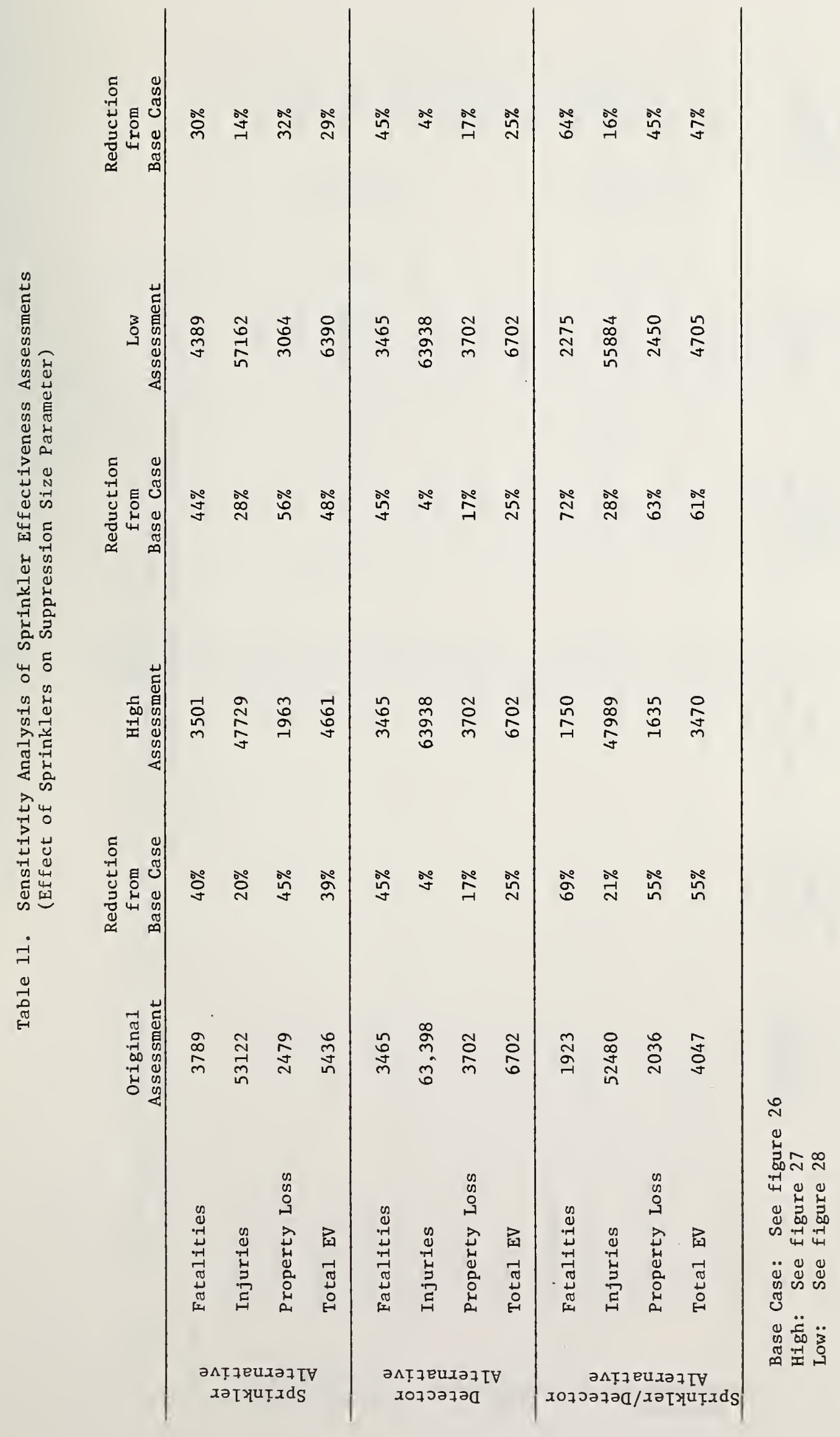




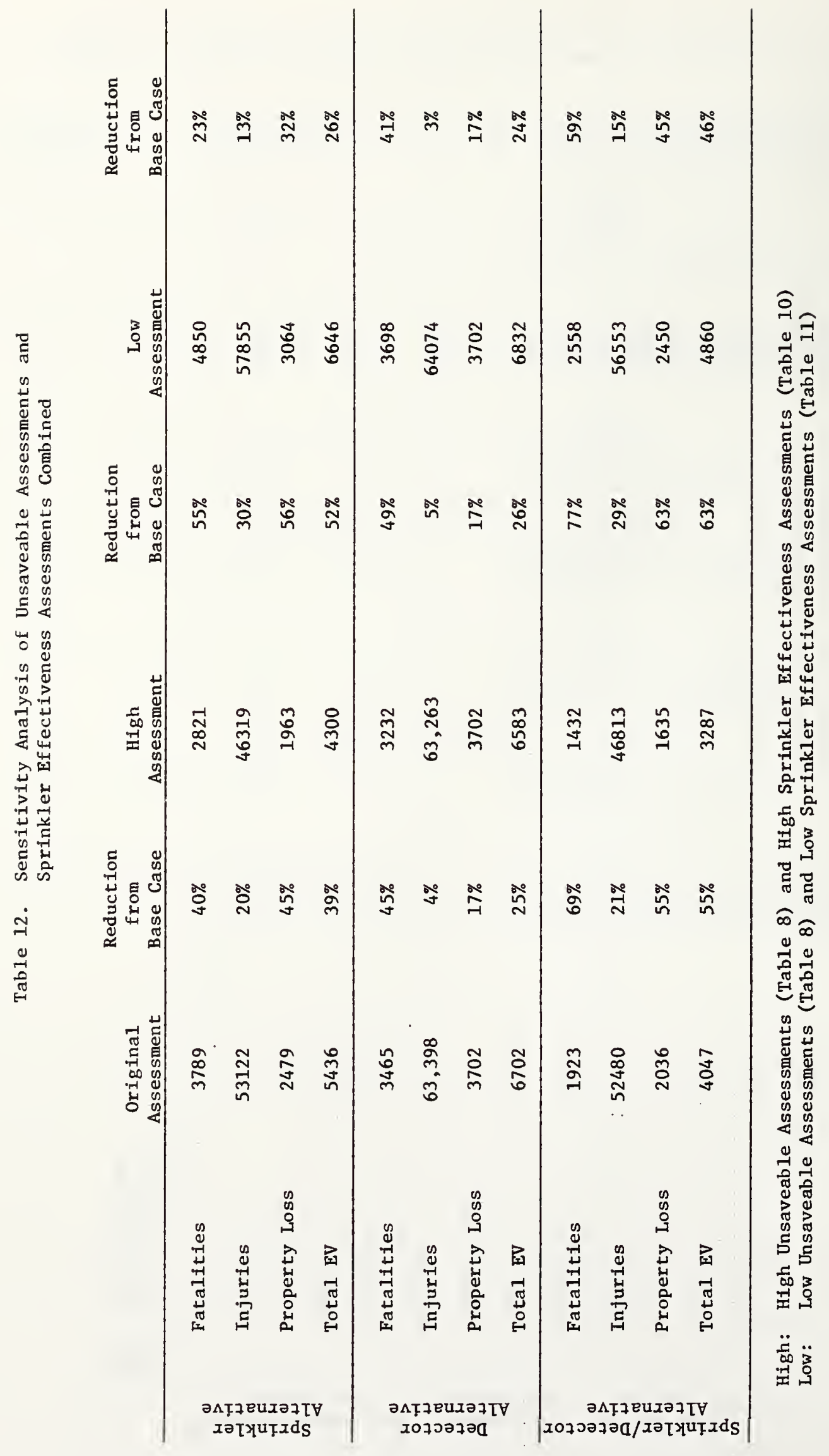


Table 13. Base Case Fire Loss Rates

One and Two Family Dwellings

$\begin{array}{lccr} & \begin{array}{c}\text { Reported } \\ \text { Fires }\end{array} & \begin{array}{c}\text { Unreported } \\ \text { Fires }\end{array} & \begin{array}{c}\text { All } \\ \text { Fires }\end{array} \\ \text { Fatalities } & 6302 & 62 & \\ \text { Injuries } & 66283 & 17400 & 21408 \\ \text { Property Loss } & \$ 4479 & \$ 450 & \$ 780 \\ \text { Total EV } & \$ 8956 & \$ 829 & \$ 1495\end{array}$

NOTE: Fatality and injury rates shown is rate per 1,000,000 fires. Property loss and total EV shown as rate per fire. 
年

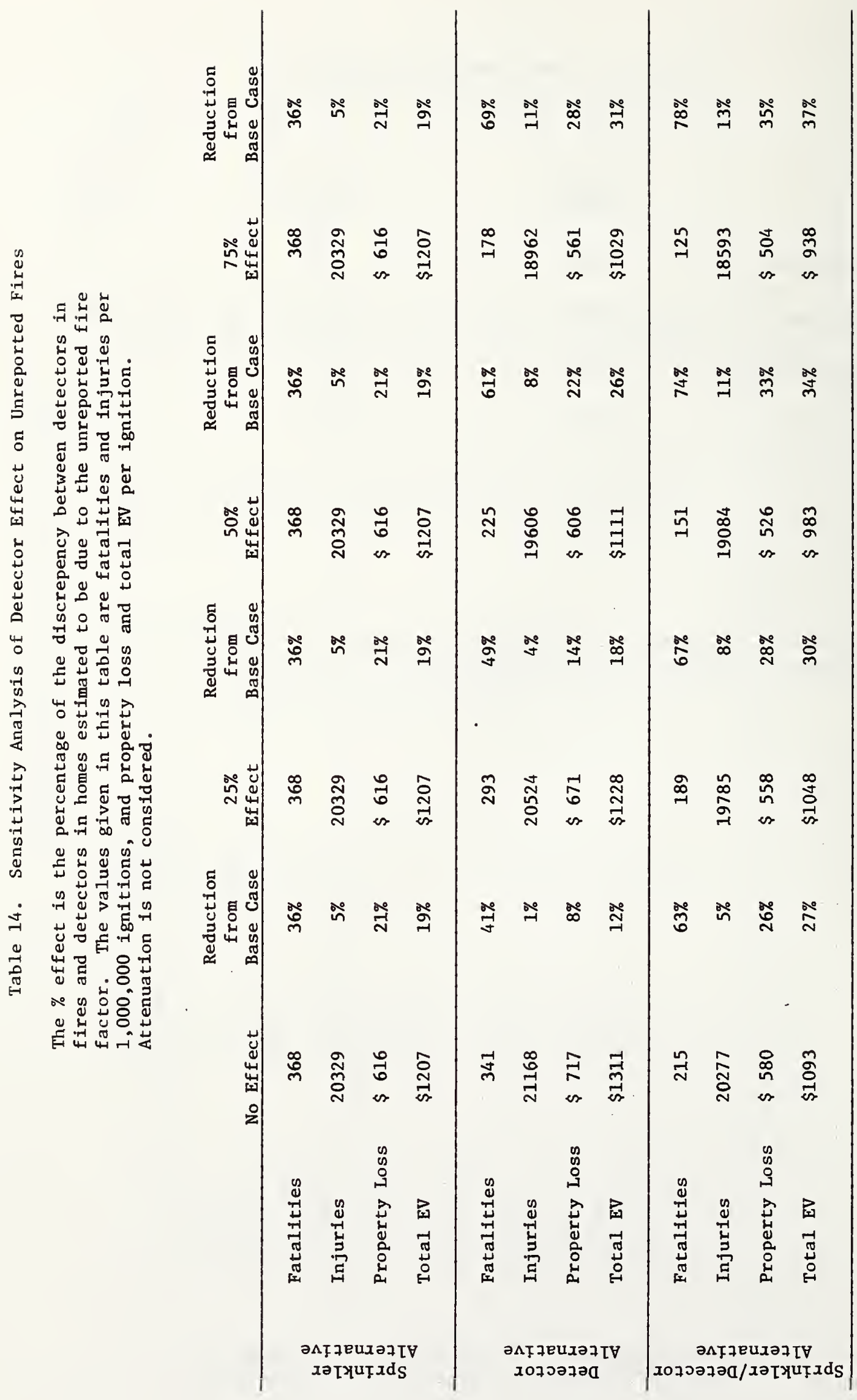


An illustration is provided of probability and loss assignments for one scenario group. The scenario group presented is Group G - interior living space fires, which is the dominant scenario group in terms of both overall losses and frequency of occurrence. Four probability trees are presented in Figures Al through A4 - the Base Case probability tree, the Detector Alternative probability tree, the Sprinkler Alternative probability tree and the Sprinkler/Detector Alternative probability tree, respectively.

Note that the loss assignments for a particular path are related only to Extent of Damage within each scenario group. Differences in total Expected Losses between alternatives, where Expected Loss is the sum of the loss assignments times the path probabilities, depends on differences in path probabilities between alternatives.

The remaining thirty-two probability trees (eight additional scenarios for the base case and three alternatives) are not documented here due to the preliminary nature of the study and for reasons of space limitation. All calculations, in computer printout form, are available at the Center for Fire Research offices. 


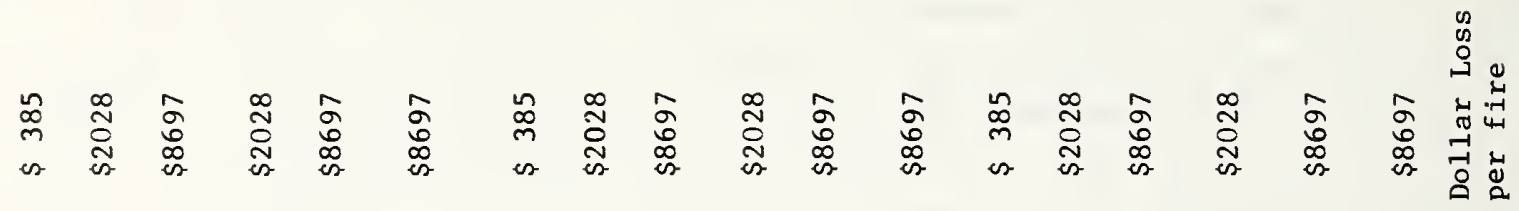

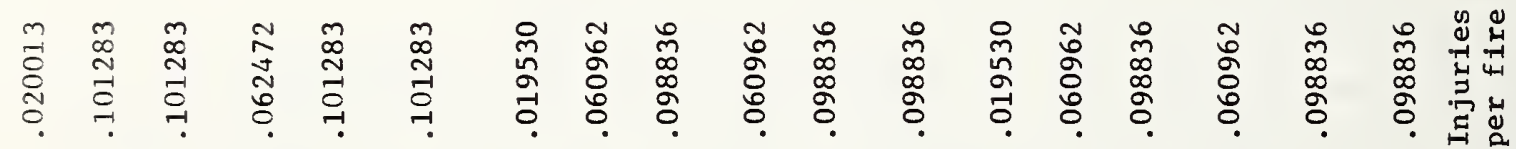

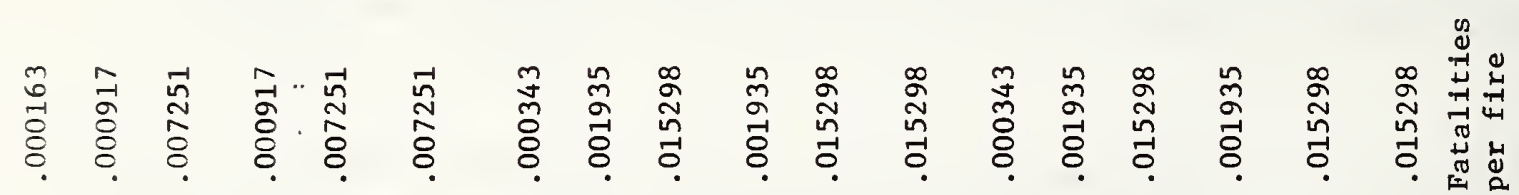

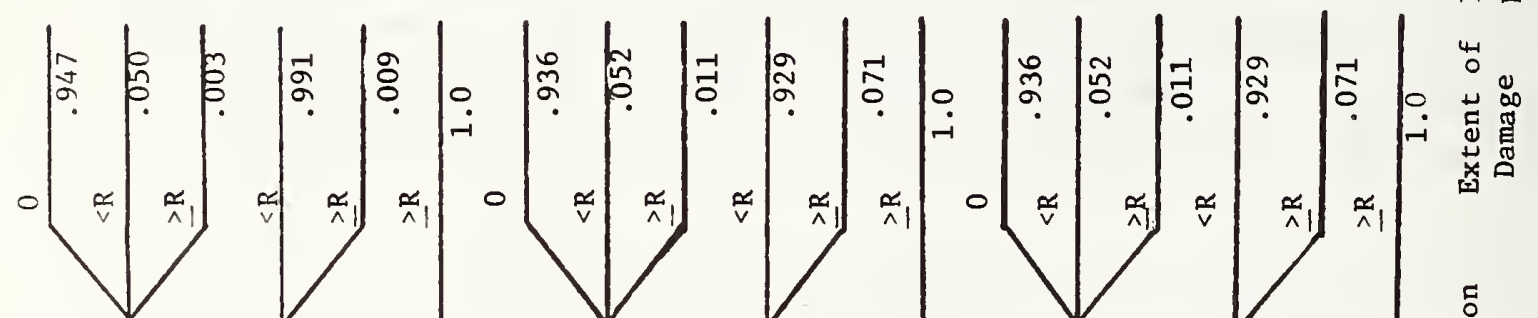

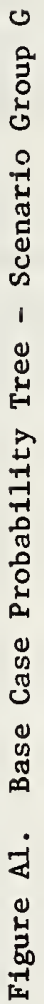

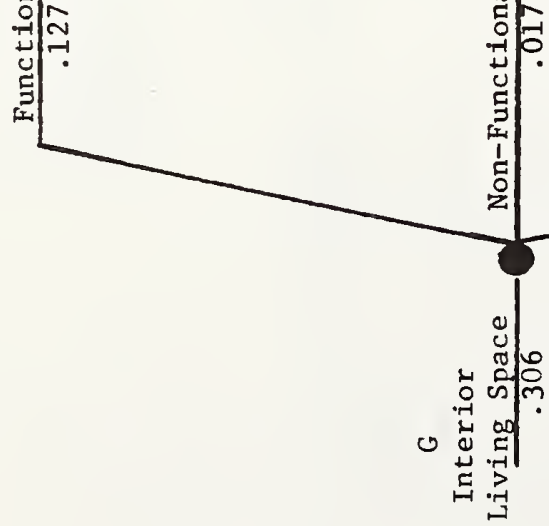




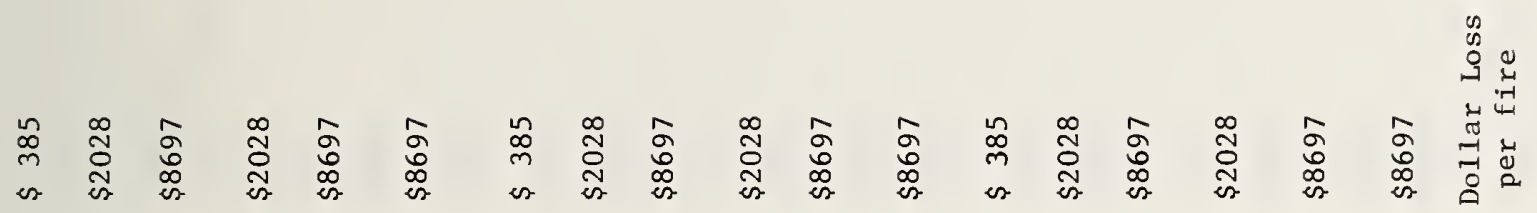

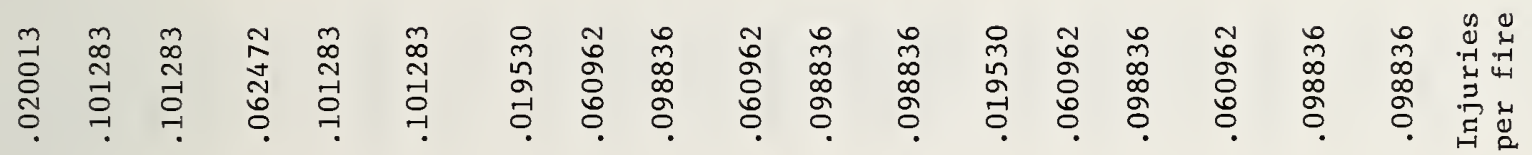

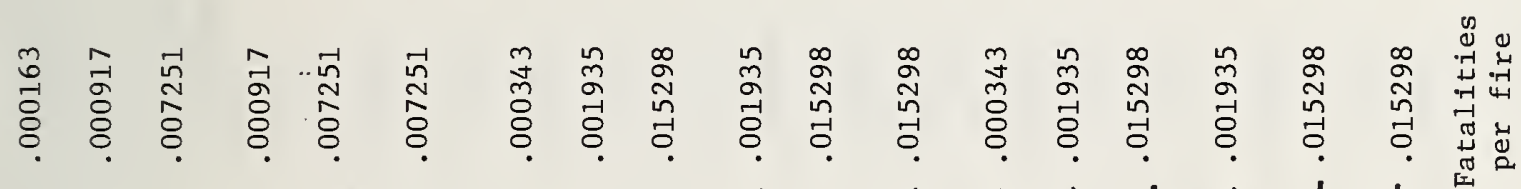

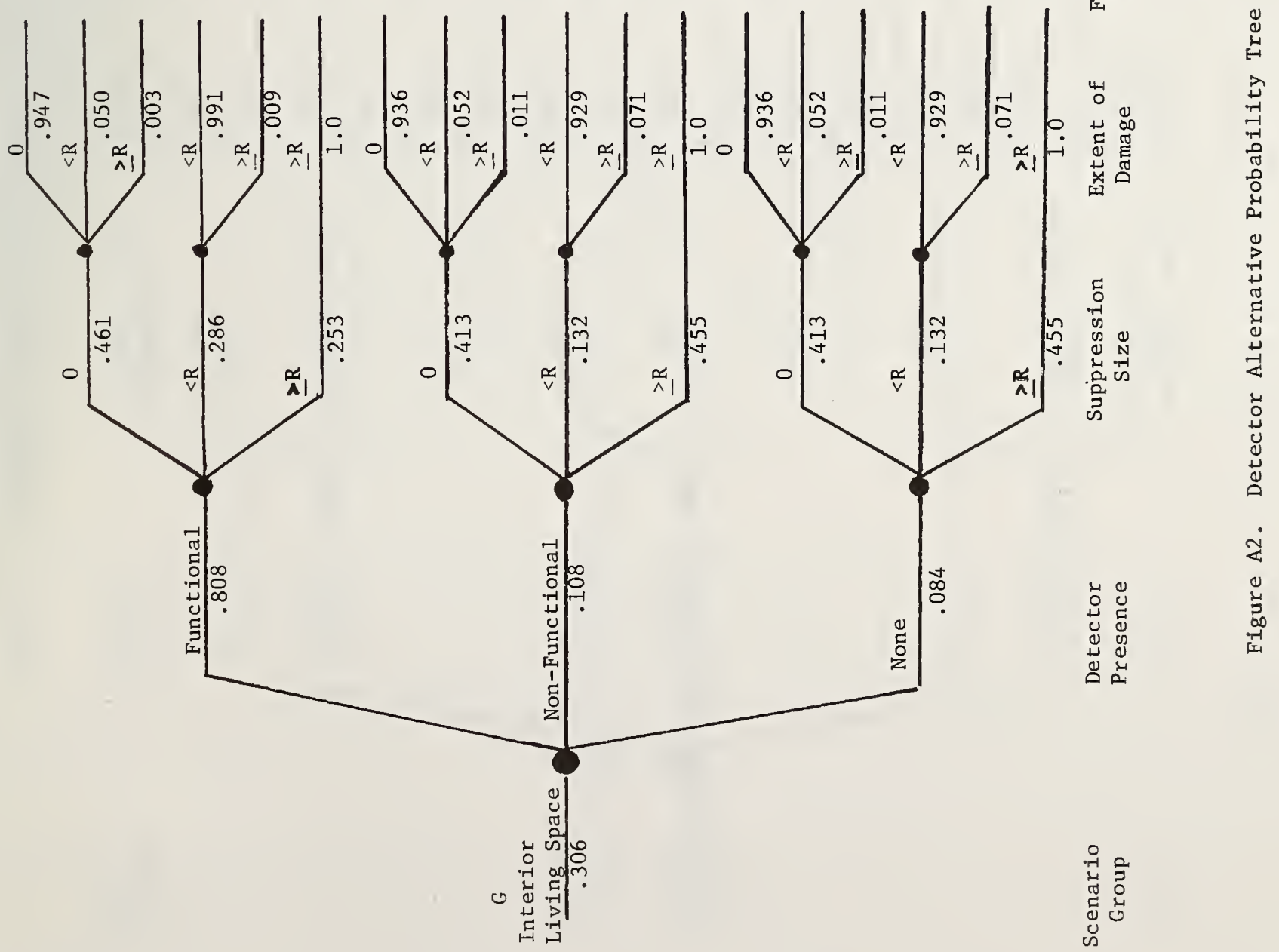




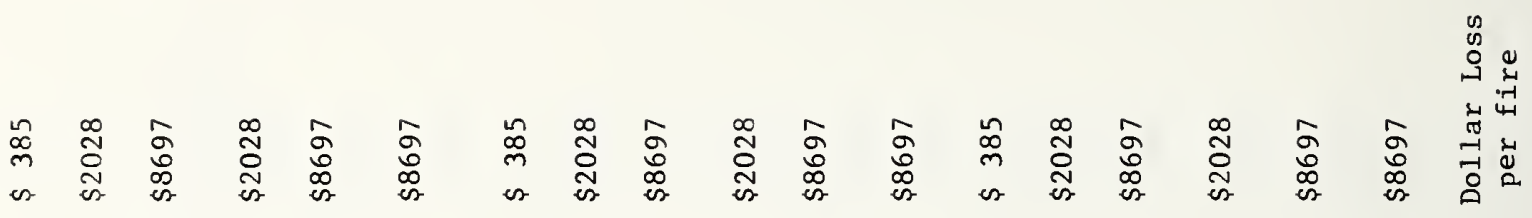

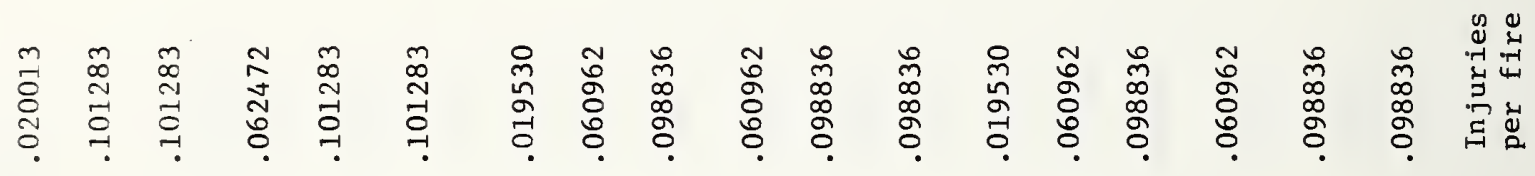

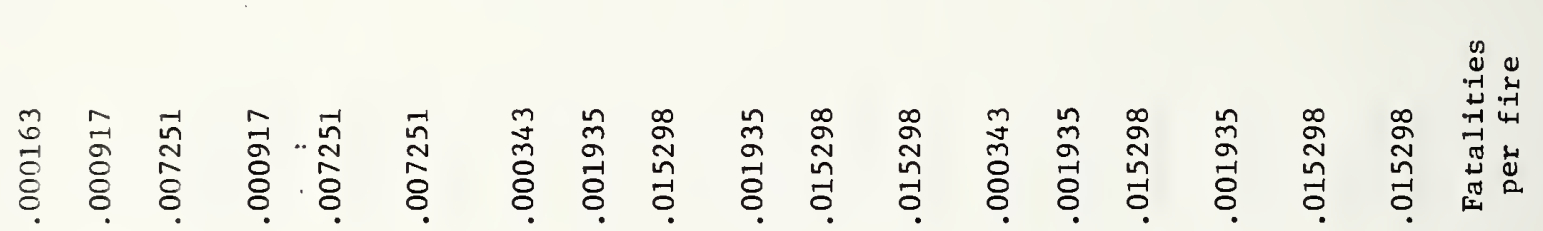

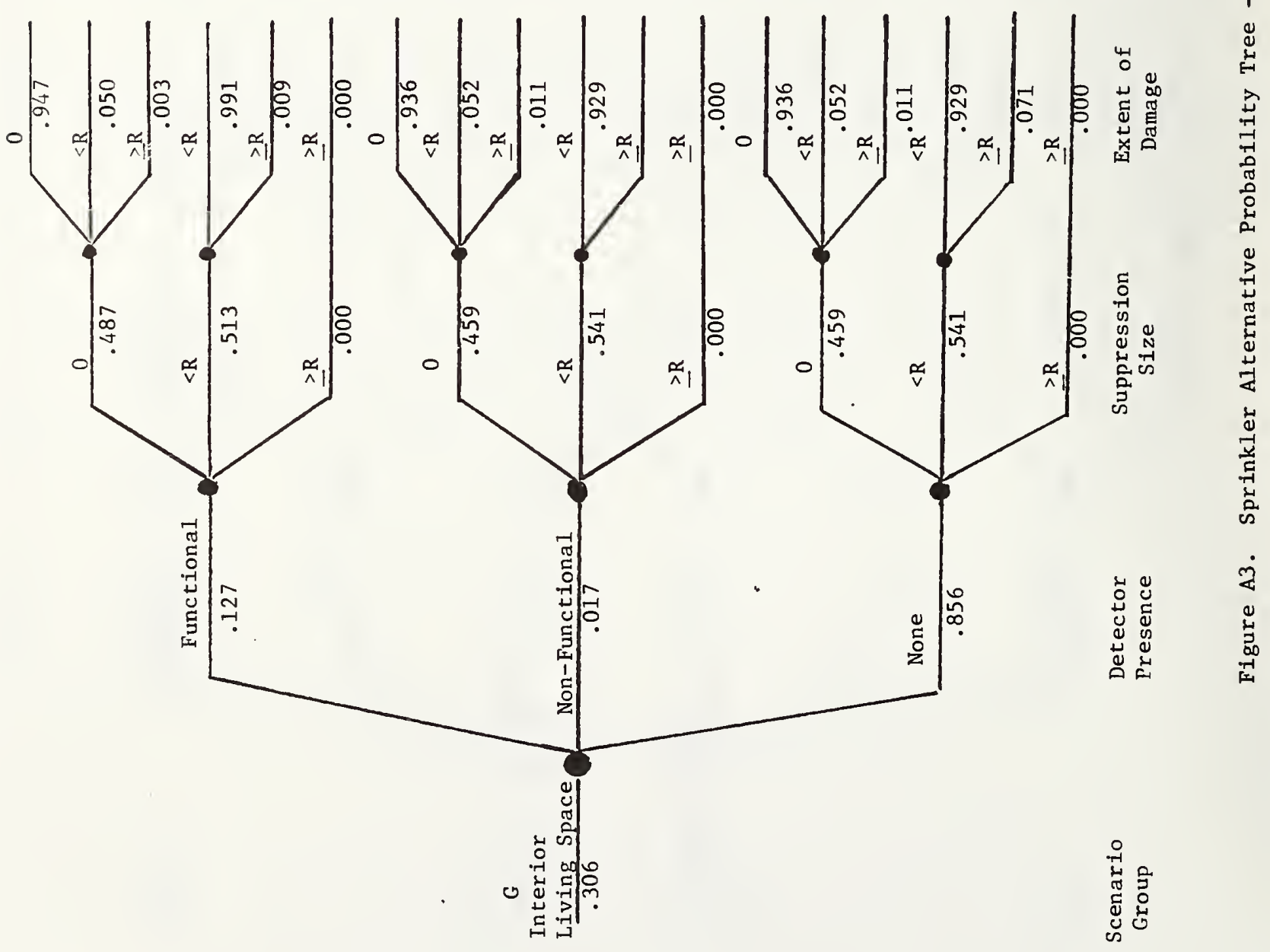




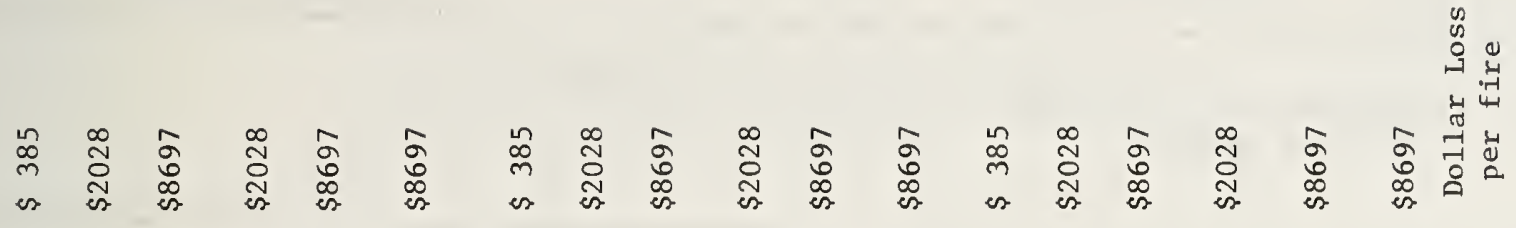

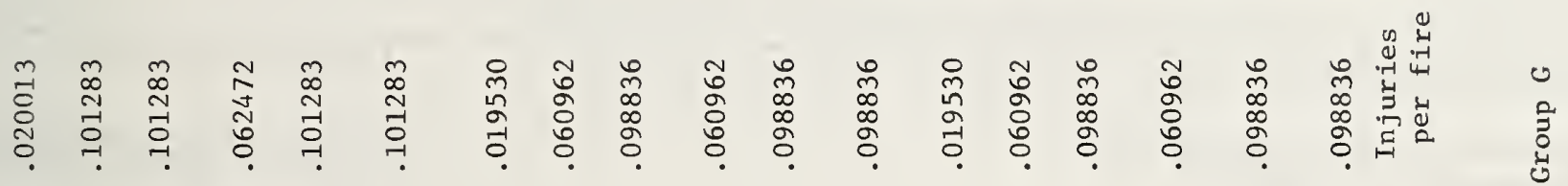

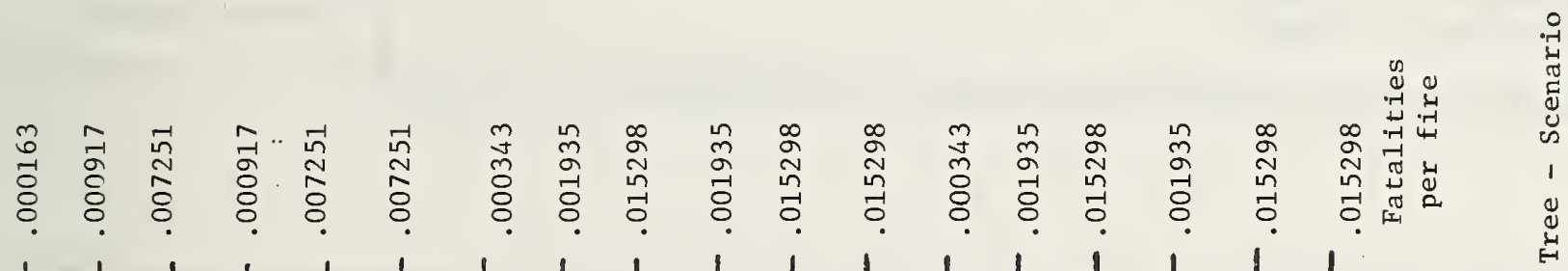

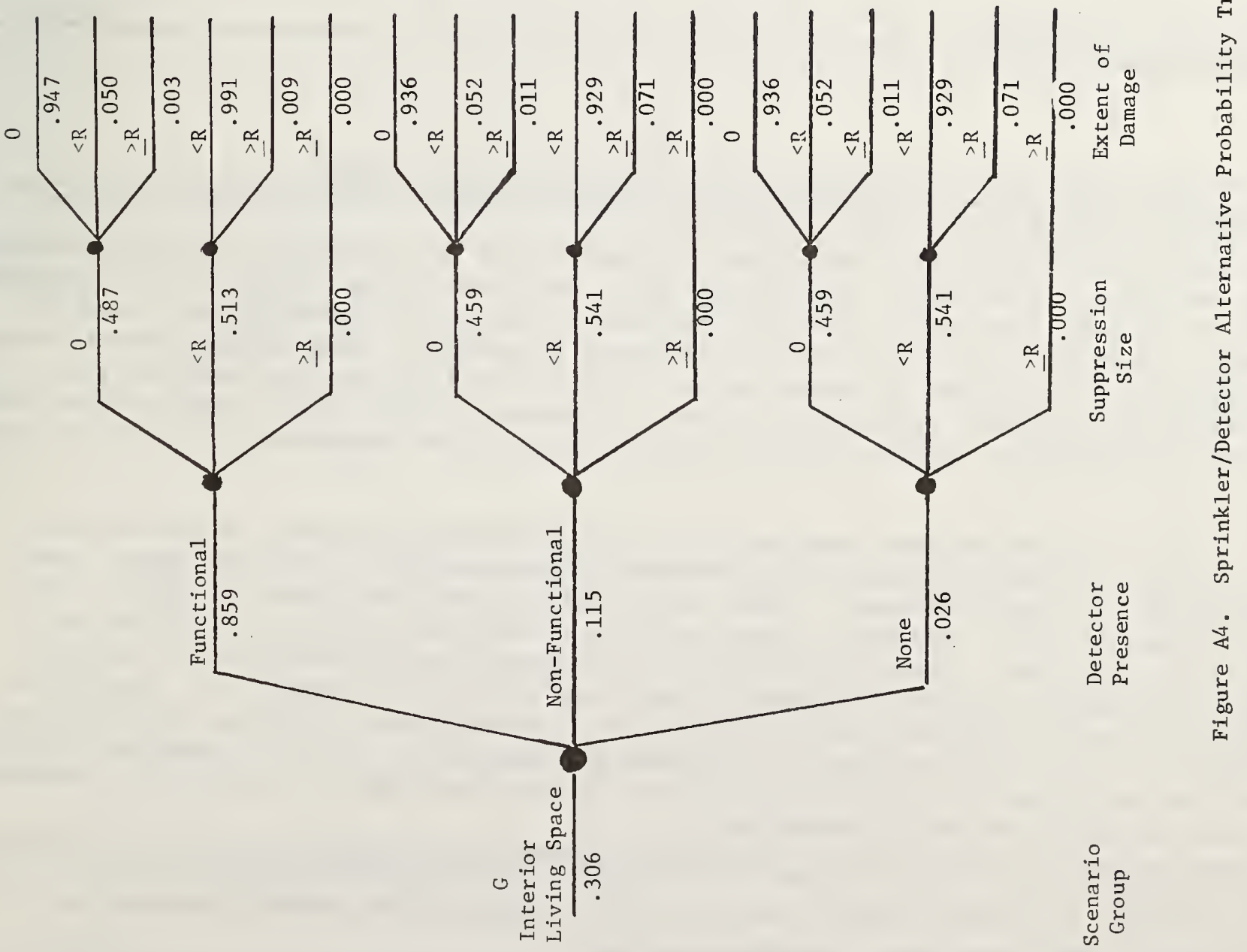


NBS. 114A (REV. 2.8C)

U.S. OEPT, OF COMM.

BIBLIOGRAPHIC DATA

SHEET (See in structions)

4. TITLE AND SUBTITLE

EVALUATING ALTERNATIVE STRATEGIES FOR REDUCING RESIDENTIAL FIRE

LOSS - THE FIRE LOSS MODEL

5. $\operatorname{AUTHOR}(S)$

Alan Gomberg, Benjamin Buchbinder and Fred I. Offensend

6. PERFORMING ORGANIZATION (If joint or other than NBS, see instructions)

NATIONAL BUREAU OF STANDARDS

DEPARTMENT OF COMMERCE

WASHINGTON, D.C. 20234

PEBLICATION OR

NBSIR 82-2551
2. Performing Organ. Report No.

3. Publication Date

August 1982

9. SPONSORING ORGANIZATION NAME AND COMPLETE ADDRESS (Street, Clty, State, ZIP)

7. Contrace/Grant No.

8. Type of Report \& Perlod Covered Interim Report

10. SUPPLEMENTARY NOTES

[-] Document descrlbes a computer program; SF-185, FIPS Software Summary, is attached,

11. ABSTRACT (A 200-word or less factual summory of most significant information. If document inciudes a significant bibliography or literature survey. mention it here)

This report provides a preliminary documentation of a decision analysis framework for evaluating alternative residential fire loss reduction strategies. The framework, when it is completed, will provide a systematic means for assessing the costs and losses occurring under different intervention strategies. The current report focuses entirely on the problem of assessing fire losses, as this is where most of the uncertainty on system performance occurs. Subsequent reports will address the cost of the alternatives, after which the alternatives can be compared on a comprehensive cost/benefit basis.

Three alternatives are considered in this preliminary report: smoke detectors, residential sprinkler systems with standard conmercial-type sprinkler heads, and a combination of both measures. Based on the preliminary input data developed, the preliminary analysis indicates that both sprinklers and detectors are effective in reducing life loss. Detectors appear to be somewhat more effective in reducing personal losses, however, because of their earlier warning capability. Sprinklers appear to be significantly more effective than detectors in reducing property loss because of their earlier start in initiating suppression. Work is underway refining the loss model and developing a cost model so that meaningful cost/benefit comparisons of the alternatives can be conducted.

12. KEY WORDS (Six to twelve entries; alphabetical order; capitalize only proper names; and'separote-key-words by semicolons) iost benefit analysis; decision analysis; fire losses; fire safety; residential buildings; smoke detectors; sprinkler systems

13. AVAILABILITY

[X. Unlimited

For Official Distribution. Do Not Release to NTIS

$\square$ Order From Superintendent of Documents, U.S. Government Printing Office, Washington, D.C. 20402.

$[X]$ Order From National Technical Information Service (NTIS), Springfield, VA. 2216I
14. NO. OF PRINTED PAGES 66

15. Price $\$ 9.00$ 

